\title{
Initial Evaluation of Fuel-Reactor Concepts for Advanced LEU Fuel Development
}

Authors:

Robert Mariani, Idaho National Laboratory Andrew Nelson, Oak Ridge National Laboratory Roger Blomquist, Argonne National Laboratory Dennis Keiser, Idaho National Laboratory Gerard Hofman, Argonne National Laboratory Gilles Youinou, Idaho National Laboratory George Griffith, Idaho National Laboratory

Contributors:

Michael Miller, Idaho National Laboratory Heather Connaway, Argonne National Laboratory James Cole, Idaho National Laboratory Eric Woolstenhulme, Idaho National Laboratory

\section{February 2020}

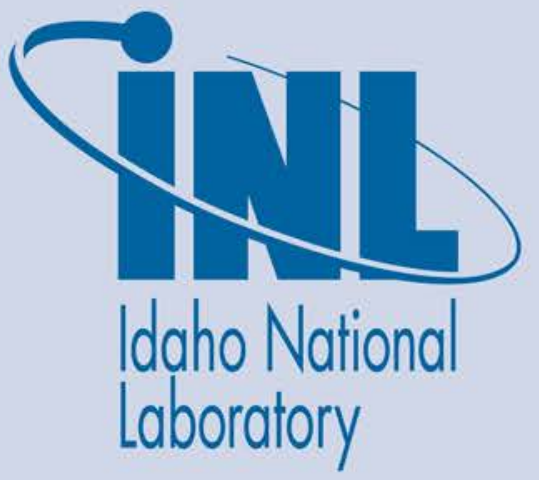

The INL is a U.S. Department of Energy National Laboratory operated by Battelle Energy Alliance 


\section{DISCLAIMER}

This information was prepared as an account of work sponsored by an agency of the U.S. Government. Neither the U.S. Government nor any agency thereof, nor any of their employees, makes any warranty, expressed or implied, or assumes any legal liability or responsibility for the accuracy, completeness, or usefulness, of any information, apparatus, product, or process disclosed, or represents that its use would not infringe privately owned rights. References herein to any specific commercial product, process, or service by trade name, trade mark, manufacturer, or otherwise, does not necessarily constitute or imply its endorsement, recommendation, or favoring by the U.S. Government or any agency thereof. The views and opinions of authors expressed herein do not necessarily state or reflect those of the U.S. Government or any agency thereof. 


\title{
Initial Evaluation of Fuel-Reactor Concepts for Advanced LEU Fuel Development
}

\author{
Authors: \\ Robert Mariani, Idaho National Laboratory \\ Andrew Nelson, Oak Ridge National Laboratory \\ Roger Blomquist, Argonne National Laboratory \\ Dennis Keiser, Idaho National Laboratory \\ Gerard Hofman, Argonne National Laboratory \\ Gilles Youinou, Idaho National Laboratory \\ George Griffith, Idaho National Laboratory \\ Contributors: \\ Michael Miller, Idaho National Laboratory \\ Heather Connaway, Argonne National Laboratory \\ James Cole, Idaho National Laboratory \\ Eric Woolstenhulme, Idaho National Laboratory
}

February 2020

Idaho National Laboratory
Idaho Falls, Idaho 83415

http://www.inl.gov

Prepared for the

National Nuclear Security Administration

Office of Defense Nuclear Nonproliferation Research and Development

Under DOE Idaho Operations Office

Contract DE-AC07-05ID14517 
INTENTIONALLY BLANK 


\section{EXECUTIVE SUMMARY}

The National Nuclear Security Administration (NNSA) Office of Defense Nuclear Nonproliferation R\&D has commenced a project to evaluate and develop low-enriched uranium (LEU) fuel systems, materials, and fabrication technologies that could be used for compact, advanced LEU (aLEU) fuel, power-producing, high-burnup reactor applications. Potential applications are intended to be off-grid power sources for ship-borne systems and transportable systems to fixed locations, e.g., to a remote base or to a seawater desalination service location. Reactors with these qualities and fuel enrichments between 5 and 20\% are atypical. The aLEU Fuel for Nonproliferation Applications Project addresses this technology gap.

In the initial stages, the team is assessing key fuel performance criteria, reactor performance criteria, and selection criteria. The project team will identify and leverage the relevant aspects of the mature knowledge base for deployed reactors, both thermal and fast reactor systems, and innovative design features that have been proposed and evaluated to varying degrees but not produced. This project assumes a uranium fuel system at an enrichment of $19.75 \%$. The team will not consider alternate fissile or fertile fuel options. The target power rating is $350 \mathrm{MWt}$, or approximately $100 \mathrm{MWe}$ with rapid load following capability from 0 to $100 \%$ power with an average power rating of approximately 20 MWe. The project assumes a single-batch core lifetime of 30 years. Fuel materials can be monolithic or dispersion, metallic, or ceramic, in rod, plate, or particle bed configurations.

Heat transfer from the fuel to the working fluid is necessary for power generation. Fuel geometry (e.g., plate, rod, other) and coolant dictate the heat transfer parameters. Limitations on core size and thermal mass make gas-cooled systems more challenging than liquid cooled. The team considered water and liquid metals first, since molten salt systems would require extensive development and demonstration of corrosion control. The linkage of coolant and reactor types affects not only performance metrics but also drive numerous requirements of the fuel-cladding system. Neutron moderation, its presence or absence, is another significant consideration. Companion reactor analyses depend on, as well as, inform the material studies of the aLEU fuel project.

To first order, reactor cooling limits the core power density. Uranium loading and fission controls limit the core life. For a given power rating, coolant, and fuel geometry, a more compact core is possible with higher uranium densities. Recognizing the relevance of uranium density, the project will consider only fuels with a density equal to or greater than $\mathrm{UO}_{2}$, such as $\mathrm{U}$-xMo alloys and UC, for further evaluation. The project is considering fuels deployed as monoliths (e.g., pellets), dispersion, or as inert matrix. The team will survey fuel systems for applicability with respect to power production, dimensional stability, technology readiness level as well as other criteria. However, demonstration of these fuels in an architecture suitable for LEU power reactor applications is limited worldwide.

The reference fuel system is monolithic $\mathrm{UO}_{2}$, used in either pellet or plate geometries. $\mathrm{A} \mathrm{UO}_{2}$ benchmark will determine reactor size, in rod and plate fuel configurations, and with water and liquid metal coolants. The project will analyze non- $\mathrm{UO}_{2}$ fuel systems to evaluate their reactor characteristics with respect to the benchmark. Monolithic fuel systems provide the most efficient use of core geometry and therefore offer efficient use of volume and mass. Assessing the deficiencies of monolithic fuels will provide the basis for future research.

Dispersion fuels are qualified fuels for research reactors, but these reactors typically run at low power and the dispersion fuels require enrichments beyond LEU if used for power reactors. To increase the uranium density, the project will emphasize the assessment of advanced fabrication and cooling methods.

Inert matrix fuel systems are similar to dispersion fuels with the exception that the matrix does not react with fuel material or fission products. This report provides examples of proposed systems, but generally, limitations fall into either fabrication processes or demonstration of reactor performance. Advanced fabrication methods have the possibility of mitigating conventional limitations and will be 
assessed in this project. Metallurgical alloying may be capable of mitigating known liabilities such as swelling in reference fuel systems. $\mathrm{UO}_{2}$ has an extensive performance database; high volume fraction $\mathrm{UO}_{2}$ inert matrix systems may provide desired performance levels. The team will explore engineering solutions to known liabilities.

The fuel survey activities are informing parallel thermal hydraulics and neutronics analyses on reactor systems. Those analyses can subsequently inform improved fuel system design, and potentially help design innovative systems. The analyses will also help in the identification of limited or crucial experimental data that is needed to help guide experiment design. Irradiation platforms include ATR (Advanced Test Reactor), TREAT (Transient Reactor Test) and HFIR (High Flux Isotope Reactor). New capabilities at each of these reactor test stations provide opportunities for more rapid assessment of irradiation performance. Ion irradiations at ATLAS (Argonne Tandem Linac Accelerator System) may help with materials studies for rapid down selection of materials for neutron irradiations.

The aLEU project aims to execute applied research with the goal of bridging this gap in technology readiness to offer a candidate LEU fuel system that meets the above reactor performance requirements. The team has ranked candidate fuel systems in two tiers. Tier 1 fuel materials, initially judged to hold more merit, include $\mathrm{UO}_{2}$, U-xMo, U-2Mo-1Si alloys, and $\mathrm{U}_{3} \mathrm{Si}$ with additions to suppress its fuel swelling. Tier 2 fuels include UC, U-10Zr, and UN. These fuel systems will be further analyzed in different configurations as monolithic, dispersion and inert matrix fuel materials, and with water and liquid metal coolants. 


\section{CONTENTS}

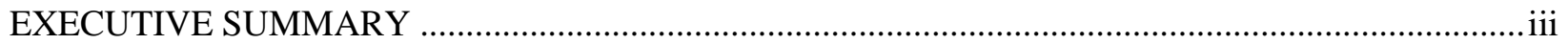

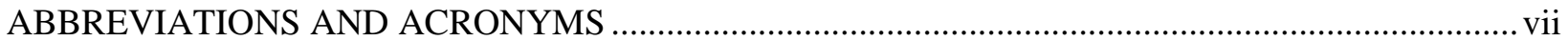

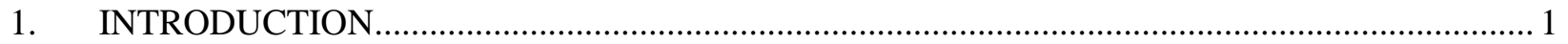

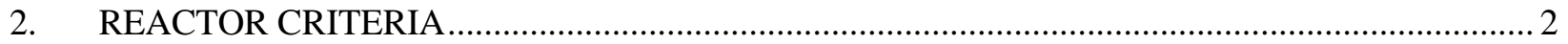

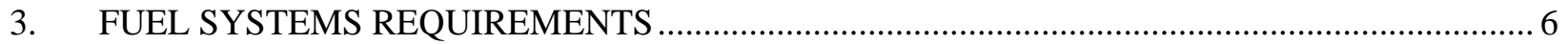

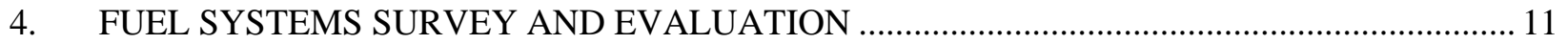

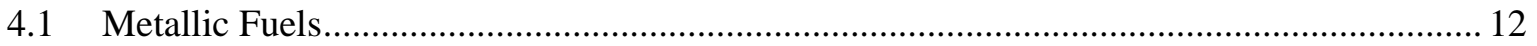

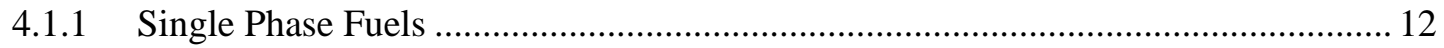

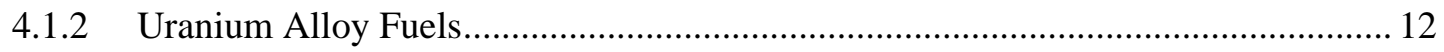

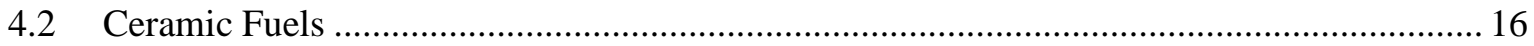

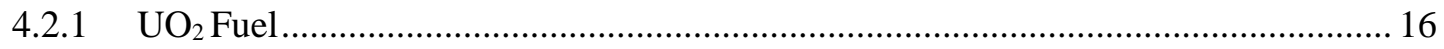

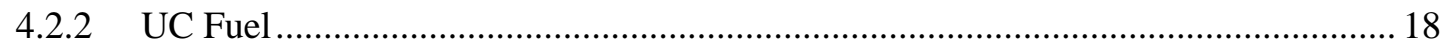

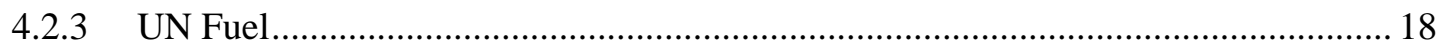

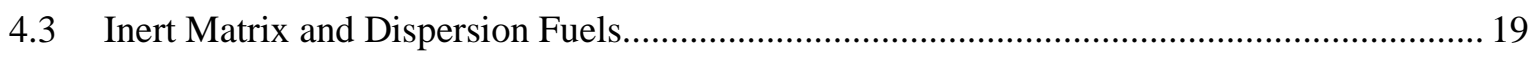

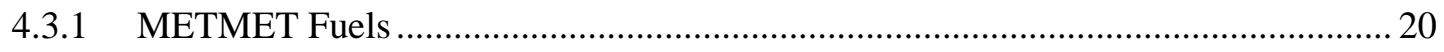

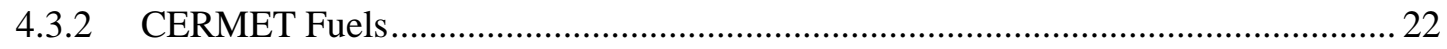

4.3.3 Metal Dispersion Fuels for Small Size Reactors.................................................... 22

$4.4 \quad$ Ideal Fuel and Recommended Fuel Systems .................................................................. 24

5. INITIAL SCREENING OF REACTOR CONCEPTS .............................................................. 25

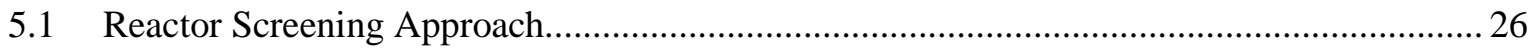

5.2 Reactor Summaries and Qualitative Assessments …........................................................ 27

5.2.1 Pressurized Water Reactors (PWR) …….............................................................. 27

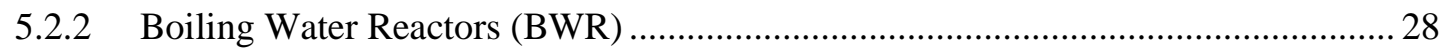

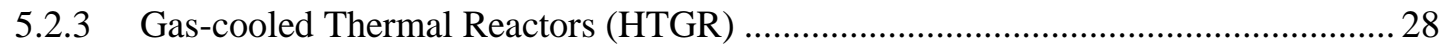

5.2.4 Heavy Water Reactors (PHWR) ……................................................................... 29

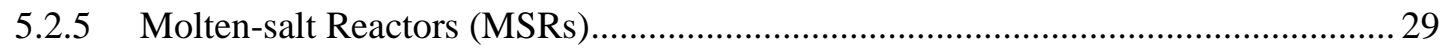

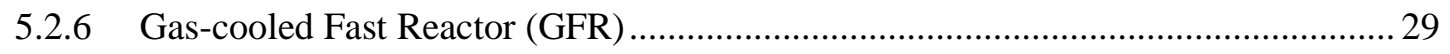

5.2.7 Supercritical Water-cooled Reactor (SCWR) …..................................................... 30

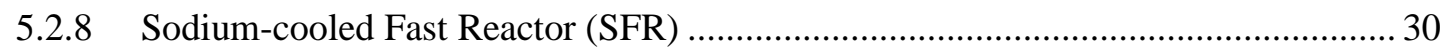

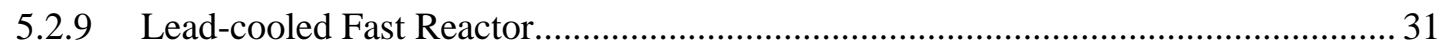

5.3 Initial Analysis of Fuel Systems and Reactor Concepts ................................................. 31

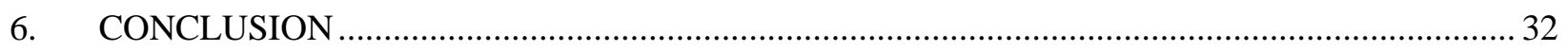

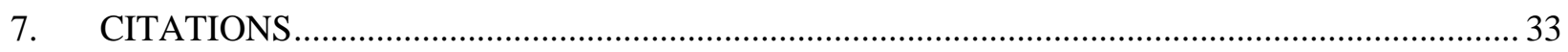

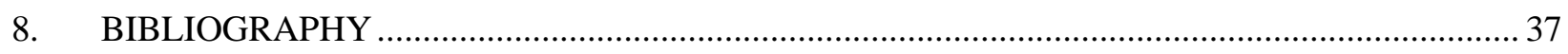




\section{FIGURES}

Figure 1. Thermal Profile for Annular Oxide Fuels with Inner Rods and Disc Separators. The model assumes rods and discs have a thermal conductivity of $20 \mathrm{~W} / \mathrm{m}-\mathrm{K}$. Peak temperatures are reduced by about $200 \mathrm{C}$ with only a modest $\mathrm{UO}_{2}$ volume decrease of approximately $7 \%$. Designs with much smaller decrease in $\mathrm{UO}_{2}$ volume are being analyzed [Mariani 2016; 2017].

Figure 2. Swelling of Some LEU Intermetallic Fuel Compounds as a Function of Accumulated Fissions [Hofman 2015].

Figure 3. Schematic representations of cladding and fuel components for compartmented plate-type oxide fuel elements. (a) Caramel fuel for the Osiris reactor; (b) fuel element for the Shippingport reactor [Cherruau 1980].

\section{TABLES}

Table 1. Brief summary of select power reactor systems with core power densities, powers and sizes [IAEA 2018a; 2018b; 2002; 2006; Prometheus 2006].

Table 2. Reactor and fuel characteristics that impact fuel system selection.............................................. 4

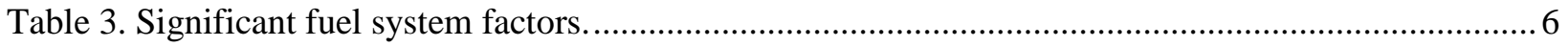

Table 4. Fuel systems with densities greater than $\mathrm{UO}_{2}$ and key criteria. Thermal conductivity data for $\mathrm{U}_{6} \mathrm{Mn}, \mathrm{U}_{6} \mathrm{Fe}$, and $\mathrm{U}_{2} \mathrm{Ti}$ not located in literature [Hofman 2015]......................................... 7

Table 5. Properties of potential LWR materials [IAEA 2003] ............................................................. 13

Table 6. Corrosion rate comparison of uranium alloys in bulk and dispersed forms [IAEA 2003]........... 20

Table 7. Swelling of uranium alloys in bulk and dispersed forms [IAEA 2003]...................................... 20

Table 8. Physical and neutronic characteristics of advanced METMET fuels for LWR (65 vol\% of fuel phase +35 vol. \% of $\mathrm{Zr}$ alloy matrix) [IAEA 2003] ..................................................... 21

Table 9. Some design and performance data for advanced fuel rods for small size reactors [IAEA 2003].

Table 10. Design and performance data for some metal fuels [IAEA 2003] ............................................ 23

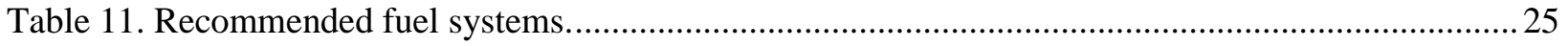

Table 12. Planned scoping analyses for selected fuel systems. ............................................................. 32 


\section{ABBREVIATIONS AND ACRONYMS}

aLEU Advanced Low Enriched Uranium

ATR

Advanced Test Reactor

bcc

body centered cubic

BOL Beginning of Life

BWR Boiling Water Reactor

CERMET ceramic-metal composite material

DOE Department of Energy

EBR-II Experimental Breeder Reactor II

FCCI Fuel Cladding Chemical Interaction

FFTF Fast Flux Test Facility

fs

fissium, an alloy including $\mathrm{U}$ with small amounts of $\mathrm{Mo}, \mathrm{Ru}, \mathrm{Pd}, \mathrm{Rh}$, and $\mathrm{Zr}$

HEU High Enriched Uranium

HFIR High Flux Isotope Reactor

HTGR High-Temperature Gas-cooled Reactor

IAEA International Atomic Energy Agency

IM Inert Matrix

INL Idaho National Laboratory

KLT-40 Nuclear fission reactors designed to power icebreakers

LEU Low Enriched Uranium

LFR Lead-cooled Fast Reactor

LWR Light Water Reactor

METMET Metal-metal composite material

MWe Megawatt electric

MWt Megawatt thermal

NNSA National Nuclear Security Administration

PHWR Pressurized Heavy-water Reactor

PWR Pressurized Water Reactor

R\&D Research and Development

SFR Sodium-cooled Fast Reactor

SMR Small Modular Reactor

TREAT Transient Reactor Test Facility

TRISO Tristructural Isotropic

TRL Technology Readiness Level 
WIMS

Winfrith Improved Multigroup Scheme (for neutronics simulations)

WNA

World Nuclear Association 


\section{Initial Evaluation of Fuel-Reactor Concepts for Advanced LEU Fuel Development}

\section{INTRODUCTION}

The National Nuclear Security Administration (NNSA) Office of Defense Nuclear Nonproliferation (DNN) R\&D (Research and Development) has commenced a project to evaluate and develop low-enriched uranium (LEU) fuel systems, materials, and fabrication technologies that could be used for compact, advanced LEU (aLEU) fuel, power-producing, high-burnup reactor applications. Potential applications are intended to be off-grid power sources for ship-borne systems and transportable systems to fixed locations, e.g., to a remote base or to a seawater desalination service location. A novel application is ship-borne to disaster relief locations such as a major city. For cities with an emergency management system within a hardened portion of their grid, a ship-borne nuclear reactor power plant could provide power for hospitals, emergency management, fresh drinking water systems, etc. A highway transportable nuclear reactor system could provide power to a land-locked city.

Reactors with enrichments between 5 and 20\% are atypical [Aydogan 2016, Simnad 1981]. Most commercial reactors are LWR-type (Light Water Reactor) with uranium enrichments less than 5\%. A few power-producing special-purpose reactor fuel systems have been developed with high enriched uranium. As an example, Experimental Breeder Reactor-II (EBR-II) developed and qualified a U-10Zr alloy fuel with $67 \%$ enrichment. More typically, however, reactors with enrichments above $20 \%$ are research or test reactors, not power reactors, which is especially true for domestic reactors. Based on enrichment alone, a significant domestic technology gap exists for compact, power-producing, high-burnup, advanced LEU fuel reactors. The aLEU Fuel for Nonproliferation Applications Project addresses this technology gap.

The project has chosen the target power rating to be $350 \mathrm{MWt}$ (megawatt thermal), or approximately 100 MWe (megawatt electric), with an average power rating of approximately 20 MWe. While power rating is specified here as a system design target, larger (1000 MWt) and smaller (100 MWt) reactor systems could be considered in future analyses, but the feasibility of target power rating may be a scaling issue or could be more involved, depending on reactor concept and fuel system design.

This document provides a summary description of reactor criteria, fuel system requirements, fuel systems survey and evaluation, and reactor concepts. It should be mentioned that the scope of this project is not to design and build a specific reactor. The reactor criteria are described to indicate the factors that restrict or influence the selection of the fuel systems. The fuel system requirements identify the factors that support specific applications, both LWR and non-LWR concepts. This qualitative evaluation provides a preliminary survey of the performance of fuel systems, and it identifies candidate systems showing the most promise. Reactor concepts have undergone an initial screening that resulted in selection of the most attractive reactor systems for further consideration. The project will give an integrated description of both modeling and experimental plans in a separate Project Plan.

Currently three Department of Energy (DOE) national laboratories-Idaho National Laboratory, Argonne National Laboratory, and Oak Ridge National Laboratory-are partnering to work in three focus areas: to identify fuel system requirements, to evaluate fabrication technologies and equipment, and to assess testing and characterization technologies and equipment. This report focuses on the first area and evaluates the feasibility of advanced LEU fuels for compact, power-producing, long-life reactors.

In the initial stages, the team is assessing key fuel performance criteria, reactor performance criteria, and selection criteria. These criteria are essential to manage the selection process of fuel systems and to accelerate quantitative progress toward the project goal. The project team will identify and leverage the relevant aspects of the mature knowledge base for deployed reactors, both thermal and fast reactor systems, and it will build on the less-mature systems that can be aligned with the project's reactor 
performance criteria. The extensive knowledge base, combined with expert contributors and a systematic approach, will expedite the progress in the three focus areas.

Several nuclear fuels and reactor programs already exist within DOE, and it is advantageous to recognize their research thrusts. Within the DOE Office of Nuclear Energy (NE), three major programs are AFC (Advanced Fuel Campaign), VTR (Versatile Test Reactor), and ART (Advanced Reactor Technologies). Another major program is the Material Management and Minimization ( $\left.\mathrm{M}^{3}\right)$ within NNSA DNN, which includes the US High Performance Research Reactor (USHPRR) and international reactor conversion projects. The Department of Energy supports NASA (National Aeronautics and Space Administration) in various compact, high-power, reactor studies for space power and propulsion applications. Private companies are carrying out other research programs. Knowledge of and experience from each of these programs will be leveraged. Collaborative engagement of research staff with experience in existing programs is advantageous in structuring the work scope so that 1) technology gaps in all the existing projects and programs can be understood and prioritized, 2) technology areas of mutual interest can advance synergistically, and 3) redundant efforts can be avoided.

This current effort evaluated a variety of fuel systems leading to recommendations of several fuel systems, in a ranked two-tier system. Analyses will be performed on non- $\mathrm{UO}_{2}$ fuel systems to evaluate their reactor characteristics with respect to the reference $\mathrm{UO}_{2}$ benchmark. Future analyses would involve the total power plant, as significant differences may arise for non-LWR systems. For the purposes of analysis, the applications are assumed to be load-following, off-grid with the ability to override Xe-fission product poisoning. In the future reactor analyses, $\mathrm{UO}_{2}$ enriched at $19.75 \%$ is adopted as the reference for determining reactor size with rod and plate fuel configurations and with water and liquid metal coolants.

\section{REACTOR CRITERIA}

The variety of nuclear reactors that have been built is comparable to the large variety of nuclear fuel materials that have been irradiated. Despite the variety, few examples meet the project goals. This variety can overwhelm a research effort with accelerated timescale, in terms of assembling and rationalizing the data available for deployed fuel systems, to deliver a novel and credible fuel system. The project is developing a methodology to recommend one or more fuel-reactor systems to meet the objectives (load-following, compact, power-producing, high burnup). For the purposes of designing a fuel system, the early literature provides some guidance [Belle 1961]. While Belle focuses on $\mathrm{UO}_{2}$, our subject matter experts found that guidance, and other sources, generally applicable. For comparison, Table 1 lists examples of power reactor systems.

The project goal is 100 MWe with a single-batch core lifetime of 30 years with representative duty cycles for the target application. Typical operation is expected to be approximately 5-30\% of full power with excursions to $100 \%$, a lifetime average of $20 \%$ of full power, and long periods of shutdown. Assuming an efficiency of approximately $28.6 \%$, the reactor design basis is $350 \mathrm{MWt}$. Fuel replacements might be considered as less impactful in some cases, where in-vessel storage is provided for fresh and spent fuel. A noteworthy feature of single-batch cores with less than $20 \%$ enrichments is that they provide enhanced non-proliferation characteristics. Compactness for some reactors is listed in Table 1, in terms of power density (i.e., per liter). For a given power requirement, the core size contains sufficient fuel mass to meet core life energy requirements. All things being equal, a single-batch core will be less compact compared to refueled cores, because fewer effective full power days would be required from a two- or three-batch core.

Reactor criteria are important to fuel system selection and design, some criteria more than others. As mentioned, the power goal is 100 MWe with rapid and repeated load following capability from 0 to $100 \%$ power without rate or restart constraints due to Xe poisoning and other effects. The reactor should respond to load-following demands after down-power from extended high-power operation. In this project, the basic premise for reactor operation is a uranium fuel system with an enrichment of $19.75 \%$. Apart from that, fuel materials can be monolithic or dispersion, metallic or ceramic, in rod, plate, or 
particle bed configurations. Table 2 lists reactor criteria the project is using to guide selection of the fuel system, and descriptions of each criterion follow.

Table 1 . Brief summary of select power reactor systems with core power densities, powers and sizes [IAEA 2018a; 2018b; 2002; 2006; Prometheus 2006].

\begin{tabular}{|c|c|c|c|}
\hline Reactor technology & $\begin{array}{c}\text { Typical Core } \\
\text { power density } \\
(\mathrm{kWt} / \mathrm{L}) \\
\end{array}$ & $\begin{array}{c}\text { Power } \\
\text { (MWt // MWe) }\end{array}$ & $\begin{array}{c}\text { Core // vessel dimensions } \\
\text { (height - diameter in } \\
\text { meters) }\end{array}$ \\
\hline Prometheus & 7.4 & $1000 / / 200$ & $0.06-0.05 / / 0.16-0.62$ \\
\hline HTGR (graphite moderator) & 5 & & \\
\hline HTR-10 & & $10 / / 0$ & $2.0-1.8 / / 10.7-4.3$ \\
\hline HTTR & & $30 / / 0$ & $2.9-2.3 / / 30-18$ \\
\hline PBMR & & $400 / / 165$ & $11-3.7 / / 30-6.2$ \\
\hline Xe-100 & & $200 / / 75$ & $\mathrm{x}-\mathrm{y} / / 20-4.9$ \\
\hline CANDU (heavy water moderator) & 20 & & \\
\hline Douglas Point (Canada) & & $693 / / 220$ & $5.9-4.5 / / 6.0-5.1$ \\
\hline KANUPP (India) & & $432 / / 137$ & $5.4-3.8 / / 5.0-4.9$ \\
\hline BWR & 60 & & \\
\hline ABWR; GE-Hitachi & & $3926 / / 1420$ & $3.8-5.2 / / 21-7.1$ \\
\hline ABWR-II; GE-Hitachi & & 4960 // 1717 & $5.4-3.7 / / 21-7.4$ \\
\hline PWR & 110 & & \\
\hline AP1000 & & $3415 / / 1100$ & $4.3-3.0 / / 12-4.0$ \\
\hline AP600 & & $1940 / / 600$ & $3.7-2.9 / / 12-4.0$ \\
\hline mPower & & $575 / / 195$ & $2.4-2.0 / / 27-4.1$ \\
\hline KLT-40 (icebreaker under construction) & & $150 / / 35$ & $1.2-1.2 / / 3.9-1.9$ \\
\hline Lead-cooled fast reactor & 150 & & \\
\hline BREST & & $700 / / 300$ & $1.1-x / / 17-26$ \\
\hline Sodium-cooled fast reactor & 400 & & \\
\hline EBR-II & & $62 / / 20$ & $0.34-0.70 / / 4.0-7.9$ \\
\hline FFTF & & $400 / / 0$ & $0.91-1.2 / / 13-6.2$ \\
\hline MBIR (under construction) & & $150 / / 0$ & $0.55-0.88 / / 12-2.5$ \\
\hline $4 \mathrm{~S}$ & & $30 / / 10$ & $2.5-0.95 / / 24-3.5$ \\
\hline MTR-plate (e.g., ATR) & 1000 & & $1.2-1.0 / / 10.5-3.6$ \\
\hline Molten salt & 1300 & & \\
\hline IMSR-400 & & $400 / / 194$ & $4.0-3.4 / / 7.0-3.5$ \\
\hline
\end{tabular}

Dimensional stability (Table 2 below) is important for the lifetime of the fuel in a single core system. Dimensional stability relates to both the fuel cladding and geometry (thermal gradients and creep), and to the fuel material. Dimensional stability includes the influence and impact of fuel swelling, creep behavior, mechanical properties, and fuel cladding mechanical interaction (FCMI). Poor dimensional stability can cause coolant flow deviations that can further distort fuel plates or rods with consequences for cooling, ultimate power, and safety margin. 
Table 2. Reactor and fuel characteristics that impact fuel system selection.

\begin{tabular}{|l|l|}
\hline Dimensional Stability & Heat Transfer \\
\hline Fission Gas Behavior & Neutronics \\
\hline Corrosion and Chemical Interactions & Fuel Density \\
\hline Thermal Performance & Technology Readiness Level \\
\hline Reactor Transients & Neutron leakage for small reactors \\
\hline Excess reactivity to overcome Xe poisoning & \\
\hline
\end{tabular}

Fission gas presents a challenge for high burnup because the reactor and fuel designs must provide for the evolution of fission gas in one of three ways: retained in the fuel, in the cladding plenum, or in a fission gas collection system. Some fuels are more capable than others in retaining fission gas. $\mathrm{UO}_{2}$ pellets as a fuel material are effective at retaining fission gas, while metallic fuels less so. Inert matrix fuels and dispersion fuels also are effective at retaining fission gas.

To achieve long core life and high burnup, minimal corrosion and chemical interactions are essential. The coolant composition must ensure long term stability of the cladding and reactor components. Likewise, the cladding must be stable toward the fresh fuel fission products. As a result, the project will not likely recommend a novel, completely untested cladding-fuel system. The project does however recognize coatings and barrier layers as a significant research prospect for corrosion mitigation, because both volatile and non-volatile fission products can migrate to the cladding-fuel interface, and because cladding-coolant corrosion reactions can degenerate cladding with longer exposure. The reactor and fuel system design must exclude the possibility of cladding breach, so that reaction between coolant and fuel is not a primary concern.

Thermal performance, particularly thermal damage resilience and stability toward fatigue, for repeated load following and accident scenarios is important. As the fuel fissions, the chemical composition and microstructure evolve, and fission products can migrate with thermochemical gradients. These phenomena will affect performance less for a fuel with good thermal damage resilience so that thermal conductivity is sustained. The design of dispersion and inert matrix fuels seeks this behavior. A more subtle consideration, good fuel design seeks a low heat capacity with high thermal conductivity. For two fuels with comparable thermal conductivities, the fuel with the lower heat capacity is more beneficial for more rapid rejection of the heat evolved and better load following. In other words, to be most effective the desired high thermal conductivity of the fuel material should derive from high density and high thermal diffusivity with a low heat capacity.

Fuels with negligible thermal fracture are ideal, or at least those whose fracture exert a minimal effect. Large thermal stress gradients can cause thermal fracture in regions between the fuel interior and fuel surface. In $\mathrm{UO}_{2}$, thermal fracture is common. Broadly speaking, features similar in effect to thermal fracture occur in alloys such as U-Zr. In metallic systems, fission gas evolution, atomic displacements, plastic flow, and temperature gradients (gradients not as extreme as in $\mathrm{UO}_{2}$ ) can contribute to morphological changes that degrade thermal performance.

The fuel system should also be robust toward variability in fuel fabrication tolerances, since dimensional instability and variability can affect fuel temperature, and lifetime. Small variations in fabrication should have negligible effect on thermal performance. For example, the designed thermal bond between the fuel and clad (i.e., whatever means is provided, such as He gas or liquid sodium) should be reproducible and sustainable for good thermal resilience.

Compact power generation requires effective heat transfer. Plate-type fuels present efficient heat transfer and a lesser concern for nucleate boiling compared to rod-type fuels. Plate-type fuels can have geometrical stability concerns though, and curved plate-type fuel designs are more commonly deployed for this reason. Rod-type fuels have a well-established history for power generation in commercial LWRs. 
Owing to the extensive history for plate-type and rod-type fuels, this project is giving both fuel types full consideration. Advanced manufacturing opportunities provide for consideration of unconventional array structures and more complex rod and plate fuels.

As noted above, effective heat transfer is required. The heat transfer characteristics of gas-cooled systems would require high pressures and high gas flow rates to reach power levels comparable to similarly sized power reactors with liquid coolants. Thus, the requirement for compactness challenges gas-cooled reactor designs in comparison to liquid-cooled systems. The project is considering as potential primary liquid coolants water, liquid metals, and molten salts. In the case of liquid metal and molten salt coolants, initial startup or restart would require an auxiliary heating system (power supply and heating mechanism). Liquid coolant at shutdown temperature is important for rapid startup to meet emergent power needs. Molten salt coolants, depending on the salt system, may also require consideration of activation products, such as the thermal neutron reaction with ${ }^{6} \mathrm{Li}$, producing tritium and ${ }^{3} \mathrm{He}$, and consequent effects on the ability to maintain plant equipment. Coolant choice also affects core lifetime in the event of cladding breach, as some fuel-coolant interactions may be relatively benign, for example, near the end of core life. It is not yet determined in this study whether any non-PWR (pressurized water reactor) concepts offer any reactor subsystem advantages. Any reactor-fuel concept will ultimately need to be evaluated in terms of total system performance. Different applications and operating environments have unique factors that impact overall power system suitability in this regard. The team recognizes some of these considerations to be beyond the scope of this study.

Neutronics present technical challenges at beginning and end of life (BOL and EOL). For a long-life core, BOL reactivity will be exceptionally high. Burnable poisons within the fuel can help control both reactivity and power distribution at startup and during transients. Another engineered solution is adjustable absorber poison in the coolant which acts a uniform core poison. The flow rate of the coolant itself can cause a spectral shift in the neutron energies; boiling water reactors have been operated in this way to reduce coolant flow at BOL and to increase coolant flow toward end of life, reducing the core coolant void fraction and softening the neutron spectrum. The increased flow acts to increase reactivity [Glasstone 2012].

Besides BOL and EOL fuel management concerns, neutron moderation affects core size. For commercial LWRs, water acts as both coolant and moderator. Moderators act to shift the neutron spectrum to lower energies across the coarse neutron energy spectrum from fast to epithermal and down to thermal. Epithermal neutrons disproportionately increase neutron capture of ${ }^{238} \mathrm{U}$ (to produce Pu after double-beta decay) as compared to neutron capture of ${ }^{235} \mathrm{U}$ to produce fission. In contrast, liquid sodium coolant does not moderate the neutron spectrum as readily. The faster neutrons are more penetrating and more "leaky" from the core, reducing reactivity and suggesting increased core size or higher enrichment than commercial PWRs use. In a fast reactor system with liquid metal coolant, reflectors can be used to increase the reactivity to make the core more compact as they can in PWRs. The extent of neutron moderation affects core size, not just core lifetime (vis-à-vis fuel lifetime). Fission product poisoning is a large effect in thermal reactors, but it is substantially reduced when there are fewer thermal neutrons.

To first order, cooling limits the core power density, and uranium loading limits the core life. For a given power rating, coolant, and fuel geometry, a more compact core is possible with higher uranium densities. Recognizing the relevance of uranium density, the project is considering only fuels with a density greater than $\mathrm{UO}_{2}$ for further evaluation. While the density of uranium in $\mathrm{UO}_{2}$ is not as great as uranium in metallic alloy fuels or $\mathrm{UC}, \mathrm{UO}_{2}$ provides some performance benefits (discussed in later sections) and extensive technological development; the TRL (technology readiness level) for $\mathrm{UO}_{2}$ is very high for its widespread research, adoption, and infrastructure [Carmack 2017].

$T R L$ for a handful of fuel systems is high. $\mathrm{UO}_{2}$ is commercially deployed in LWRs. The U.S. DOE qualified U-10Zr alloy fuel for use in Experimental Breeder Reactor-II. In ATR, UAl ${ }_{\mathrm{x}}$ fuels have been deployed. Two fuel systems are presently being qualified in ATR: U-xMo alloy fuels (dispersion and 
monolithic) for NNSA and AGR-TRISO (Advanced Gas Reactor-Tristructural Isotropic) for the ART program (Advanced Reactor Test). HFIR uses a high-enriched $\mathrm{U}_{3} \mathrm{O}_{8}$ dispersion fuel. Union Carbide extensively researched UC in the 1960s. TRIGA (Training, Research, Isotope production, General Atomics) fuel also is well characterized. Extensive irradiation experience also exists outside the United States for $\mathrm{U}_{3} \mathrm{Si}_{2}$. While the design goals for this project's fuel system combined with the lack of deployed examples make the TRL for this project low from the outset, the extensive deployment of other fuel systems will be leveraged. Mainly, the methods for fabricating, characterizing fresh fuel, irradiating, post-irradiation examination, and qualifying fuel are well established. For $\mathrm{UO}_{2}$, all aspects of the infrastructure are extensive and at a high TRL.

The fuel system must allow for reactor transients at start-up and for rapid changes in load following. Particularly at start-up, the fuel system must provide assurances against reactivity insertion accident scenarios. For both start-up and for rapid increases in power demand, the safety margin against fuel melting must be high, owing to a high fuel melting temperature, efficient heat transfer (e.g., guarding against nucleate boiling) or both. The project is weighing the issue of loss of coolant accident scenarios, what to include or exclude, reactor-fuel systems that require trained operator intervention, or those that are passively safe.

As suggested in the discussion to this point, non-LWR fuel systems are also being evaluated. These include U-xMo alloy (dispersion and monolithic), U-10Zr alloy, and UC, among others. Each appears to meet the reactor criteria described to this point. These non-commercial, non-LWR fuel systems have reached a high TRL in one application or another, though not with perfect application to the goals of this project. However, it is recognized non-LWR systems may involve overall power system requirements in implementation that simplify or complicate deployment of the total system.

\section{FUEL SYSTEMS REQUIREMENTS}

Significant fuel system factors are listed in Table 3. Some of these topics are described above, as reactor criteria that drive selection of fuel systems. More discussion is offered below as to the potential advantages of characteristics such as uranium density, fuel type (plate, rod or particle), fuel material (i.e., chemical composition), fuel form (monolithic, dispersion, or inert matrix), etc. Since it is impossible to quickly discharge failed fuel elements, the fuel must be very reliable. These factors and characteristics can be ranked to develop fuel system requirements and to evaluate the different fuel systems considered.

Table 3. Significant fuel system factors.

\begin{tabular}{|l|l|}
\hline Fuel Material Chemical Composition & Neutron Moderation \\
\hline U density greater than that for $\mathrm{U}_{\text {in } \mathrm{UO}_{2}}$ & Fuel Swelling and Shrinking \\
\hline Thermal Conductivity $\geq \mathrm{UO}_{2}$ & Manageable Thermal Fracture \\
\hline Fuel Type: rod or plate & Fission Gas Management \\
\hline Fuel Form: monolithic, dispersion, inert matrix & FCCI (Fuel Cladding Chemical Interaction) \\
\hline Reproducible Fuel Fabrication & Shock Loading \\
\hline Manageable Chemical and Microstructural Flux & TRL \\
\hline Fuel Reactivity with Coolant & Coolant Reactivity with Environment \\
\hline
\end{tabular}

Fuel systems considered in this project are listed in Table 4. Uranium fuel material categorizes the fuel systems with respect to chemical composition. Dispersion and inert matrix fuels are alternatives, but they would alter the actual fuel chemical contents and lower the uranium density. The fuel materials in Table 4 derive from consideration of two key criteria: uranium density and thermal conductivity. As mentioned, following the effects of coolant and neutron moderation on compactness, a higher uranium density contributes to a smaller critical volume. The project has chosen $\mathrm{UO}_{2}$ as the lower limit on uranium density. Incidentally, all fuel systems with a uranium density less than that for $\mathrm{UO}_{2}$ also have a very low 
TRL. Table 4 indicates melt temperature, which is a coarse indicator of safety margin. A more complicated relationship, between peak fuel temperature, melting temperature, and upper coolant temperature, exists to determine safety margin. Nonetheless, a high melting temperature with low peak fuel temperature provides a better safety margin than high melting and high peak temperatures. As Table 4 indicates, the project is considering a number of potential fuel systems to this point.

Table 4. Fuel systems with densities greater than $\mathrm{UO}_{2}$ and key criteria. Thermal conductivity data for $\mathrm{U}_{6} \mathrm{Mn}, \mathrm{U}_{6} \mathrm{Fe}$, and $\mathrm{U}_{2} \mathrm{Ti}$ not located in literature [Hofman 2015].

\begin{tabular}{|c|c|c|c|c|c|}
\hline $\begin{array}{l}\text { Uranium } \\
\text { Fuel } \\
\text { Material }^{\mathrm{a}} \\
\end{array}$ & $\begin{array}{c}\text { Calculated } \\
\text { Phase Density } \\
\left(\mathbf{g} / \mathbf{c m}^{3}\right)\end{array}$ & $\begin{array}{c}\text { Calculated } \\
\text { Uranium } \\
\text { Density } \\
\left(\mathbf{g} / \mathrm{cm}^{3}\right) \\
\end{array}$ & $\begin{array}{c}\text { Melt T } \\
\text { [C] }\end{array}$ & $\begin{array}{l}\text { Thermal Cond. } \\
\text { W/m-K@ } 20 \text { C }\end{array}$ & $\begin{array}{c}\text { Fuel Swelling } \\
\text { Experience }^{\mathrm{b}}\end{array}$ \\
\hline U metal & 19.0 & 19.0 & 1135 & 27 & - \\
\hline U-7Mo & 17.5 & 16.3 & 1180 & 16 & DR, MP: hi bu \& low T \\
\hline $\mathrm{U}_{6} \mathrm{Mn}$ & 17.8 & 16.1 & $730 *$ & - & DR: low T \\
\hline $\mathrm{U}_{6} \mathrm{Fe}$ & 17.7 & 16.1 & $815^{*}$ & - & DR: low T \\
\hline U-10Mo & 17.2 & 15.5 & 1200 & 12 & DR, MP: hi bu \& low T \\
\hline $\mathrm{U}_{3} \mathrm{Si}$ & 15.6 & 14.9 & $930 *$ & 13 & $\begin{array}{l}\text { DP, DR: hi bu \& hi T; } \\
\text { SR: low bu \& hi T }\end{array}$ \\
\hline U-10Zr & 16.0 & 14.4 & 1230 & 17 & MR: hi bu \& hi T \\
\hline UN & 14.3 & 13.5 & 2805 & 15 & MR: hi bu \& hi T \\
\hline UC & 13.6 & 12.7 & 2530 & 22 & MR: hi bu \& hi T \\
\hline $\mathrm{U}_{3} \mathrm{Si}_{2}$ & 12.2 & 11.3 & 1665 & 8 & DP, DR: hi bu \& low T \\
\hline $\mathrm{U}_{2} \mathrm{Ti}$ & 15.2 & 11.1 & 1235 & - & - \\
\hline $\mathrm{UO}_{2}$ & 10.9 & 9.7 & 2850 & 9 & DP, MR: hi bu \& hi T \\
\hline
\end{tabular}

Fuel thermal conductivity is high for metallic fuels and for two ceramics, UN and UC. Thermal conductivity is important for safety margin. For a given fuel geometry, stored energy is less for a fuel with higher thermal conductivity. At a given linear power, a higher thermal conductivity provides a lower peak fuel temperature. Lower peak fuel temperature means lower additional pressure from fission gas, and it means smaller thermal gradient in the fuel. Inert matrix fuels can provide a boost to thermal conductivity and stabilize it during burnup, in fuels such as $\mathrm{UO}_{2}$.

Both rod and plate-type fuel are viable for this project. Both fuel types have a high TRL for all aspects of deployment and qualification, from fabrication to PIE and modeling, although no single implementation is perfectly aligned with this project. Each fuel type has advantages and disadvantages compared to the other. In addition, novel fuel systems may be considered, such as arrays of encapsulated particle fuel, depending on how such a design might rank against other criteria.

For both rod and plate-type fuels, the fuel forms can be monolithic, dispersion, and inert matrix. Dispersion fuels present a uniform distribution of fuel in a matrix. Inert matrix fuels (IM fuels) provide a matrix that does not chemically react with the fuel material and minimally (or not at all) reacts with fission products. Oftentimes, IM fuel designs seek a more structured array of fuel particles in a matrix. Of the three fuel forms, monolithic and dispersion fuels have a high TRL in deployment, while inert matrix less so. Both dispersion and inert matrix fuels necessarily reduce the uranium density within the fuel element, since their practical load limit is on the order of 55-60 volume percent using conventional 
fabrication methods. Dispersion and inert matrix fuels are therefore better matched with higher density fuel phases, such as U-7Mo, if deployed, while monolithic allows for lower density fuels such as $\mathrm{UO}_{2}$.

Novel fuel geometries for these fuel materials are an important consideration, partly because of advancements in accident tolerant fuels and partly because of recent initiatives in advanced manufacturing. For example, recent modeling results have shown that annular fuel pellets with annular rods and discs between pellets (Figure 1) can reduce peak BOL oxide fuel temperatures from $2000 \mathrm{C}$ to $1100 \mathrm{C}$, and routine operating temperatures from $1100 \mathrm{C}$ to less than $800 \mathrm{C}$ (at $400 \mathrm{~W} / \mathrm{cm}$ linear heat generation rates). Conceptually this fuel system can be compared to inert matrix, and it certainly comprises all the benefits of inert matrix fuels (low temperature gradient, reduced fuel cracking, better fission gas retention with lower temperatures and pressures, reduced fuel fragmentation under loss-of-cooling accident: LOCA) while permitting fuel loadings on the order of 90 volume percent and greater. This novel design and comparable improvements to it have been proposed for testing in TREAT.

Reproducible fuel fabrication is currently routine for both fuel types (rod and plate) and for all three fuel forms (monolithic, dispersion and inert matrix). $\mathrm{UO}_{2}$ pellets, certain metal alloys (U-xMo), and some particle fuels (TRISO) currently have high TRLs associated with their fabrication. Others such as U-10Zr and UC have had high TRLs for fuel fabrication in the past, but the lack of extensive recent fabrication activities would require recapturing past methods and techniques. As implied under Section 2, fuel fabrication must be reproducible enough to have negligible impacts on fuel performance within the tolerances of the fuel specification. Factors such as gap between fuel and cladding $\left(\mathrm{UO}_{2}\right)$, microstructural texture in cladding, bow and straightness (rod-type), curvature (plate-type), mechanical properties such as hardness, etc.: these all have a bearing on fuel performance, especially long-term, high burnup applications. For some factors, either the reactor design needs to be forgiving and insensitive to the variability in the fuel system, or the fabrication process needs to accommodate tight tolerances. The fuel specification and fabrication operation must recognize and distinguish between those that are impactful and those less so.
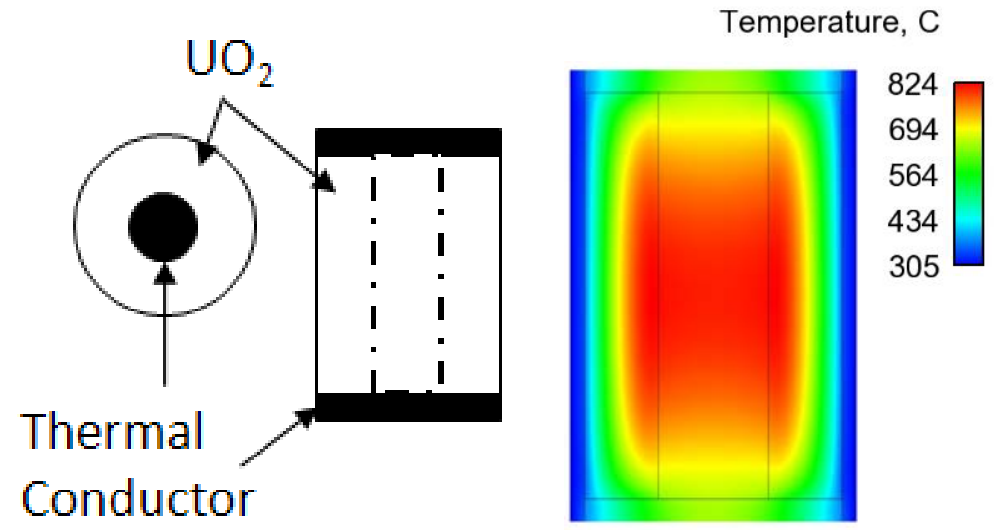

Figure 1. Thermal Profile for Annular Oxide Fuels with Inner Rods and Disc Separators. The model assumes rods and discs have a thermal conductivity of $20 \mathrm{~W} / \mathrm{m}-\mathrm{K}$. Peak temperatures are reduced by about $200 \mathrm{C}$ with only a modest $\mathrm{UO}_{2}$ volume decrease of approximately $7 \%$. Designs with much smaller decrease in $\mathrm{UO}_{2}$ volume are being analyzed [Mariani 2016; 2017].

Reproducible fuel fabrication also applies to the use of coatings and barrier layers, as applied to either fuel or cladding. High burnup fuel systems employ coatings or barrier layers. Two examples are TRISO fuel and U-xMo. Both of these fuels are being qualified in ATR. For U-xMo fuel, both coatings (dispersion fuel) and barrier layers (monolithic fuel) are being investigated. More recent R\&D efforts in coatings and barrier layers have been directed toward accident tolerant fuels. It should be mentioned that coatings and barrier layers for this project holds a very low TRL, and their use would require research and development. The important outcome is this: for any coating or barrier layer used, whatever 'qualities' it 
possesses and benefits it confers—in coherence, chemical composition, thermodynamic stability, corrosion resistance, etc.- - it must be reproducible and predictable in service. Some performance benefits can be assessed from modeling, but R\&D in this area is also at a low TRL. The only modeling capabilities with strong history in this area relate to thermodynamic, CALPHAD-type (CALculation of PHAse Diagrams) modeling. Despite the lack of maturity in the application of coatings and barrier layers to nuclear materials, their R\&D is essential for long-term, high burnup applications; the high burnup fuels cited above, as well as their extensive successes in the aerospace and semiconductor industries, urge their consideration.

Fuel swelling and shrinking will be managed or accounted for, as these aspects can affect coolant flow, creep, cladding rupture, and safety margin. Various phenomena give rise to fuel swelling: cavitation, breakaway swelling, bubble and pore growth (especially in metallic alloys), solid fission product swelling, and fuel cracking (fracture) and fuel fragmentation. The latter two phenomena are more common to ceramics, like $\mathrm{UO}_{2}$. These different mechanisms are often collectively modeled through a fuel relocation parameter in power reactors; however, fuel fragmentation is more associated with fuel response to an accident than to routine operation.

Cavitation causes significant fuel swelling, as in pure uranium. Intermetallic compounds, such as $\mathrm{U}_{6} \mathrm{Fe}$, are associated with a similar extent of swelling (Figure 2) as they become amorphous during irradiation. It may be mentioned that the intermetallic compounds are just that, regular polycrystalline compounds throughout, and distinguishable from alloys in their constitution (some alloys are however ordered).

Fission gas contributes to fuel swelling, especially for metallic fuels; fission gas is known to have a smaller effect on $\mathrm{UO}_{2}$ swelling as compared to metallic fuels. Fission gas must be managed in high burnup fuels. Since fission gas behaves differently in different fuel systems, deployed fission gas management systems include entrapment in the fuel material, inert matrix fuels, and a fission gas plenum. Some combination of these three can be useful, such as encapsulation found in TRISO fuels, where the fuel material is encased in a three-layer system with $\mathrm{SiC}$ and carbon, and the particles are combined and pressed into pellets in practically what amounts to an inert matrix.

Thermal fracture also relates to fuel swelling. For example, steep thermal gradients in $\mathrm{UO}_{2}$ fuels induce thermal fracture. For $\mathrm{UO}_{2}$, some volume increase naturally results, but the potentially larger effect is the impact of fracture on thermal conductivity, should the fracture lines isolate the fuel hot spots from the fuel surface near the cladding. 


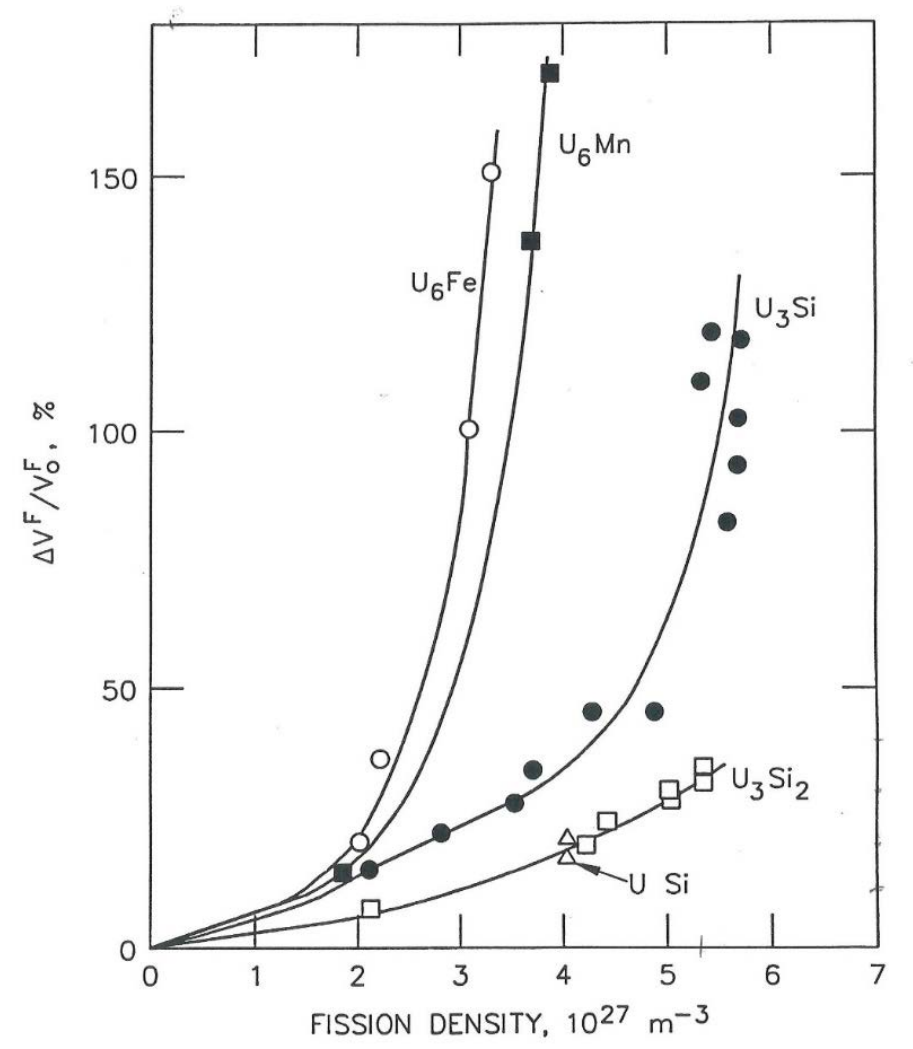

Figure 2. Swelling of Some LEU Intermetallic Fuel Compounds as a Function of Accumulated Fissions [Hofman 2015].

Fuel shrinking occurs when the fuel densifies, especially at elevated temperatures. It can also result as an artifact of the fuel shape at elevated temperature. When the cladding dimensions follow fuel shrinkage, adverse circumstances similar to fuel swelling can result. Fuel shrinking is more common with ceramic fuels (e.g., $\mathrm{UO}_{2}$, UC, and $\mathrm{UN}$ ) in early life as compared to metallic fuels, due to the presence of initial porosity in fresh fuel after sintering.

Fission product migration and fuel redistribution can cause fuel cladding chemical interaction (FCCI). Fission products that migrate to the cladding can initiate corrosion and wastage of the cladding, reducing fuel life or possibly requiring thicker claddings. In all known fuel systems with high burnups (greater than 50\%), fission product-cladding or fuel-cladding chemical interactions have required a coating or barrier layer. U-10Mo monolithic plate fuel employs a zirconium layering around the fuel plate. U-xMo dispersion fuel has employed coatings on the fuel particles. TRISO fuel employs a three-layer system to encapsulate the particle. These observations illustrate that barrier layers can be applied to fuels, pellets or plates, besides the possibility of coating and barrier layers applied to cladding (interior and exterior).

A brief discussion of neutron moderation was given in the Reactor Criteria section. Regarding fuel specifications, dopants (e.g., samarium, hafnium, gadolinia or erbia) can be used as a burnable poison to smooth out reactivity during startup. With high burnup, the variability in microstructure can be a concern for water-cooled $\mathrm{UO}_{2}$ fuels owing to activation of ${ }^{238} \mathrm{U}$ at the perimeter of the fuel body, while the burnup profile is more uniform for the harder neutron spectrum when using a liquid metal coolant.

Reactivity of coolant with fuel constituents and reactor materials is a concern depending on the safety margin for operation and the degree of reactivity. The reactor design does not tolerate cladding breach for continued operation. However, it is conceivable that a reactor might allow for continued operation with a cladding breach, depending on the reactivity of the fuel with the coolant and maintaining a geometry with 
cooling functionality. The issue becomes the avoidance of serious complications that might arise from evolution of corrosion products or generation of by-products such as $\mathrm{H}_{2}$ gas. Irradiated fuel reaction with coolant is a concern to be addressed especially with water coolant, and possibly less so for metal fuels with liquid sodium coolant.

For liquid sodium coolant, elemental sodium is very reducing so that corrosion of structural components is much less a concern than for water. Sodium might cause differential leaching of chemical elements from structural materials, but experience with EBR-II did not give evidence to that effect. Liquid sodium systems must preclude contact with air and water, especially. Neutron activation of sodium can lead to high radiation levels that preclude human access to plant systems for periods on the order of three weeks.

Liquid lead and lead-bismuth alloys are not quite as reducing. These liquid metal coolants exhibit some challenges in managing the oxygen potential $\left(\mathrm{pO}_{2}\right)$ in the coolant system and the potential for corrosion of the coolant system. At this stage of the project, the total power system is not the primary focus. Future considerations, beyond the scope of this present study, however, must take into account the total power system, not just the reactor and fuel system.

$T R L$ has been discussed in connection to Reactor Criteria. Many non-commercial, non-LWR fuel systems have deployed fuel systems with high TRLs. This project will apply the relevant knowledge of their qualification and extensive irradiation histories.

\section{FUEL SYSTEMS SURVEY AND EVALUATION}

Over the last several decades, researchers investigated different nuclear fuel systems for application in power and research reactors. A recent document captures the bulk of this work up to 2003 [IAEA 2003]. Investigators looked at a wide variety of fuel systems all over the world for many years, and many results are relevant to identifying fuel systems for further investigation in an advanced LEU fuel system. This survey uses the historical information to identify leading fuel systems as candidates for off-grid application in compact, power producing, loading following systems. The project primarily seeks engineering solutions, based on the abundance of literature, and novel scientific solutions secondarily, such as innovative alloys offer.

To reiterate, Section 3 provides some information on fuel phases (e.g., compounds), fuel types (rod, plate, particle), and fuel forms (monolithic, dispersion and inert matrix). For clarity, it may be mentioned that fuel rods can be produced as stacked pellets or as cast slugs encompassing the entire fuel length. Plate fuel can be produced flat or curved. Particle fuel can be used as pressed pellets or in a packed bed.

Monolithic fuels are surveyed first, with a subdivision into metallic fuels and ceramic fuels. The metallic fuels are divided into the categories of single phase and alloys. Ceramic fuels in this report include $\mathrm{UO}_{2}$, UC, and UN. More complex ceramic systems have been irradiated; however, these complex ceramics are often cited as advanced, for both their "potential” advantages and for their low TRLs. While the low TRLs of advanced ceramic systems do not promote their adoption within this project, this survey does describe some examples. Besides the monolithic fuel form, the two other forms are inert matrix and dispersion fuels, and they are described with reference to the potential fuel phases and their possible forms.

The discussion of the fuels systems here leads to the characteristics of the ideal fuel, and those characteristics are given at the end of this section. Fuel phases recommended for further evaluation and development are provided, with their potential drawbacks and key unknowns requiring development. This specific content informs the reactor concepts analysis described in the next section. This survey also points out conceptual areas for seeding and exploring potential innovative systems to foster their emergence, alongside systems with high TRLs. 
The amount of data for fuel systems is encyclopedic in character, especially for the well-researched systems. For this reason, the fuels with more abundant data and high TRL are discussed less, while data for lesser known fuels are presented with detail sufficient for their qualitative analysis in comparison of the more common fuel systems.

\subsection{Metallic Fuels}

Fuels of metallic uranium are categorized as single phase or alloy. Single phase includes pure uranium metal and intermetallic compounds such as $\mathrm{U}_{6} \mathrm{Ni}$ and $\mathrm{U}_{6} \mathrm{Fe}$. Both $\mathrm{U}_{3} \mathrm{Si}_{2}$ and $\mathrm{U}_{3} \mathrm{Si}$ exhibit metallic properties generally but behave a little differently under irradiation. Specifically, $\mathrm{U}_{3} \mathrm{Si}_{2}$ shows more ceramic-like properties under irradiation. These two uranium silicides are discussed in this section. Alloy systems include U-10Zr, U-xMo, U-Zr-Nb, and U-fissium [Hofman 1994a, Saller 1956]. The latter two are not listed in Table 4, but they will be briefly discussed in this section because of some noteworthy features.

\subsubsection{Single Phase Fuels}

Metallic uranium and the intermetallics compounds (such as $\mathrm{U}_{6} \mathrm{Fe}$ ) swell considerably (expand) under irradiation. For uranium metal, the swelling behavior is described as cavitation, with large voids being introduced between neighboring crystal planes as stresses build with anisotropic expansion and displacements. For the intermetallics, the uranium phase transforms to an amorphous state that is more susceptible to fission gas swelling as compared to a regular lattice. The swelling behavior can be remedied in large measure with the addition of small amounts of impurities in the alloys. While the high uranium densities for intermetallics make them attractive, their unpredictable swelling rules them out, except for possible application as dispersion or inert matrix fuel forms. In the early years, the cavitation and gross swelling phenomena led the whole community away from metallic and toward oxide fuels. For this reason, the project is not considering the following pure phases as a fuel material: $U_{,} \mathrm{U}_{6} \mathrm{Ni}, \mathrm{U}_{6} \mathrm{Fe}$, $\mathrm{U}_{6} \mathrm{Mn}, \mathrm{U}_{2} \mathrm{Ti}$, and $\mathrm{U}_{3} \mathrm{Si}$. However, $\mathrm{U}_{3} \mathrm{Si}$ still holds some interest when alloyed and applied in an inert matrix fuel.

Like $\mathrm{U}_{3} \mathrm{Si}, \mathrm{U}_{3} \mathrm{Si}_{2}$ is single phase. $\mathrm{U}_{3} \mathrm{Si}_{2}$ does not exhibit the large swelling characteristics nearly as much as $\mathrm{U}_{3} \mathrm{Si}$. $\mathrm{U}_{3} \mathrm{Si}_{2}$ has received recent focus for power applications as an accident tolerant fuel in LWRs. The uranium density of $\mathrm{U}_{3} \mathrm{Si}_{2}$ is low however, in comparison to the alloys such as U-7Mo. Also, the typical application of $\mathrm{U}_{3} \mathrm{Si}_{2}$ is fueling research reactors as a dispersion fuel, which lowers the uranium density even further. While $\mathrm{U}_{3} \mathrm{Si}_{2}$ has uranium density a little higher than that for $\mathrm{UO}_{2}$, it has no high temperature data. For those two weaknesses combined, the project recommends no further consideration of $\mathrm{U}_{3} \mathrm{Si}_{2}$ as a fuel.

\subsubsection{Uranium Alloy Fuels}

The initial work in developing fuels for thermal and fast reactors focused on uranium-based metallic fuel, but later in the 50's and 60's other fuels were investigated (e.g., oxides, carbides, nitrides, and silicides). Having early demonstration of some technical and economic advantages, oxide fuels became the major focus for global use in nuclear power plants with thermal and fast reactors. However, research and propulsion reactors did not share the same focus as large reactors with high power demands. Smaller reactor applications attracted broader research efforts, and they permitted exploration of metallic matrix and fissile uranium compounds. The corrosion resistance of various binary and multi-component uranium alloys in water and steam was investigated. Alloys with a structure free from the alpha-uranium phase demonstrated corrosion resistance. Alloy development proceeded with U-2Zr-3Nb (weight\%), on a base of metastable uranium $\alpha^{\prime \prime}$-phase, and with U-5Zr-5Nb and U-9Mo, on a base of metastable uranium $\gamma$-phase. Researchers also investigated the compound $\mathrm{U}_{3} \mathrm{Si}$ with additions of $\mathrm{Ti}$ for alloying, since this fuel has some metallic properties [IAEA 2003]. 
The structural stability of these alloys under irradiation at different temperatures was investigated. This research established maximum operating temperatures for the following alloys: $250^{\circ} \mathrm{C}$ for $\mathrm{U}-2 \mathrm{Zr}-3 \mathrm{Nb}, 450^{\circ} \mathrm{C}$ for U-5Zr-5Nb, and $500^{\circ} \mathrm{C}$ for U-9Mo [IAEA 2003]. At higher temperatures, the more stable uranium $\alpha$-phase forms, resulting in a sharp decrease in the water corrosion resistance of these alloys. As the structure of the alloy U-2Zr-3Nb appeared unstable under conditions of water-cooled power reactors, the research on this fuel was stopped.

$\mathrm{U}_{3} \mathrm{Si}$ retains its native structure when irradiated, which might lower the corrosion resistance with increasing temperature. Researchers used micro-additions of transition metals ( $\mathrm{Ti}, \mathrm{Zr}, \mathrm{Nb}$ ) to the uranium to improve its corrosion resistance, and this proved to be very effective. Canadian researchers obtained other results on the improvement of the water corrosion resistance. They selected a metallurgical solution, alloying $\mathrm{U}_{3} \mathrm{Si}$ with aluminum at a concentration up to $1.5 \%$.

Table 5 gives some properties of alloys envisaged as potential fuels for water-cooled power reactors, in comparison with $\mathrm{UO}_{2}$ and unalloyed $\mathrm{U}$.

In the design of long-life fuel rods with metallic fuel, fuel swelling must be considered. To reduce the swelling of the metallic fuel, it is important to establish and remedy the swelling mechanisms. The three types of swelling are solid fission product swelling, fission gas bubble swelling and breakaway swelling.

The accumulation of solid fission products causes solid swelling, since their specific volume is larger than the specific volume of the uranium atom. The estimated rate of solid swelling is about 0.64 vol\% per fission density $10^{20} \mathrm{~cm}^{-3}$ (for pure $\mathrm{U}$ - about 3 vol\% per 1 at\% burnup). Solid swelling is inevitable and cannot be suppressed, because solids are the most difficult to compress (i.e., compared to gases and liquids). Good fuel design must make some allowance for solid swelling.

Table 5. Properties of potential LWR materials [IAEA 2003].

\begin{tabular}{|c|c|c|c|c|c|}
\hline Property & $\mathrm{UO}_{2}$ & $\mathrm{U}$ & $\mathrm{U}_{3} \mathrm{Si}$ & $\mathrm{U}-5 \mathrm{Zr}-5 \mathrm{Nb}$ & U-9Mo \\
\hline Density theoretical, $\mathrm{g} / \mathrm{cm}^{3}$ & 10.96 & 19.07 & 15.58 & 16.64 & 17.51 \\
\hline Content of uranium, $\mathrm{g} / \mathrm{cm}^{3}$ & 9.66 & 19.07 & 14.99 & 14.98 & 15.76 \\
\hline $\begin{array}{l}\text { Parasitic neutron capture } \\
\text { by alloying elements, } \\
\text { barns per one U atom }\end{array}$ & 0.0004 & 0 & 0.043 & 0.17 & 0.68 \\
\hline \multicolumn{6}{|l|}{$\begin{array}{l}\text { Thermal conductivity, } \\
\mathrm{W} /(\mathrm{m} \cdot \mathrm{K}) \text { : }\end{array}$} \\
\hline $200 \mathrm{C}$ & 4.0 & 31 & 24 & 22 & 17 \\
\hline $500 \mathrm{C}$ & & 36 & 38 & 41 & 37 \\
\hline $\begin{array}{l}\text { Linear expansion } \\
\text { coefficient, } 10^{-6} \mathrm{~K}^{-1}\end{array}$ & 9 & 18 & 15 & 20 & 17 \\
\hline $\begin{array}{l}\text { Corrosion rate in water at } \\
300 \mathrm{C}, \mathrm{mg} /\left(\mathrm{cm}^{2} \mathrm{~h}\right)\end{array}$ & stable & 1000 & 1.1 & 0.11 & 0.08 \\
\hline
\end{tabular}

The precipitation and subsequent growth of fission gas (Xe and $\mathrm{Kr}$ ) bubbles causes bubble swelling. The fission yield of $\mathrm{Xe}$ and $\mathrm{Kr}$ is $\sim 0.25$ per fission. Theoretical analysis shows that bubbles are in equilibrium at temperatures lower than $300 \mathrm{C}$ and at fission density higher than $10^{21} \mathrm{~cm}^{-3}$. Specifically, the surface tension of the matrix counterbalances the internal bubble pressure. In the temperature range of 350 to $550 \mathrm{C}$, a gas-vacancy mechanism governs the formation of bubbles, because under these conditions there is an excess of vacancy flow in the matrix. The internal bubble pressure is then lower than that under equilibrium conditions. One may conclude this temperature range represents a maximum for the swelling. For temperatures higher than $600 \mathrm{C}$, the swelling cannot be restrained using technically 
acceptable measures (e.g., increase of the coolant pressure, use of strong cladding and cold outer layers of the fuel, etc.).

When swelling relates to fission gas and atomic vacancies, swelling can be reduced under certain conditions. The level of restraint will depend on the diameter of the gas-vacancy bubbles. For uranium and uranium alloys, the bubble size at a burnup of about $15 \mathrm{MWd} / \mathrm{kg} \mathrm{U}$ is of the order of $0.1 \mu \mathrm{m}$. Hydrostatic pressure on the order of $40 \mathrm{MPa}$ could be used to achieve a significant reduction of the swelling, but this is unrealistic for current fuel pin designs. For comparison, in $\mathrm{U}_{3} \mathrm{Si}$ fuel, the size of the gas-vacancy bubbles at the same burnup is larger, around $0.5 \mu \mathrm{m}$, but a pressure somewhat less than 10 MPa is sufficient for achieving a swelling reduction [IAEA 2003].

When irradiation growth causes crystal blocks to separate and deform in unmatched fashion, breakaway swelling occurs. This kind of swelling occurs in alloys. Breakaway swelling has a mechanical origin, and an excess vacancy flow is needed for its evolution. Breakaway swelling is developed at the same temperature range as gas-vacancy swelling. Breakaway swelling is characterized as the presence of extended cavities having "unrigid” plate-like geometry. Experiments in Canada, France, UK and USA demonstrate that a hydrostatic pressure less than $10 \mathrm{MPa}$ is required for the complete suppression of the breakaway swelling. Reportedly, fuel pins with the alloys U-9Mo and U-5Zr-5Nb are "rigid" under irradiation. The decomposition of the $\gamma$-phase in the central hot zone of the pin, producing $\alpha$-U, can complicate the use of these alloys in power reactors [IAEA 2003].

4.1.2.1 U-xMo Alloy Fuels. U-10Mo and U-7Mo have been tested extensively to high burnup in research reactors. Both alloy compositions have been tested as solid plate and dispersion plate fuel. The US HPRR program is currently qualifying a U-10Mo monolithic plate fuel with a Zr barrier layer between the fuel plate and cladding. However, this program focusses on low temperature research reactor applications, not power producing reactors.

To meet the goals of this project, U-xMo fuel would need to be tested at higher temperatures in-pile, temperatures corresponding to power production. Irradiations could be conducted at ATR and TREAT with PIE performed at HFEF (Hot Fuel Examination Facility) and IMCL (Irradiated Materials Characterization Laboratory). Some well-designed, out-of-pile testing would be useful. Some historical irradiated samples, which have not undergone PIE, are relevant to this project, plans are being made to select and evaluate them.

Fission gas behavior is manageable in the U-xMo fuels because of the metastable bcc (body centered cubic) fuel phase present. The fission gas forms an extremely stable fcc (face centered cubic) bubble lattice within the fuel material for reasons unknown (which are presently being investigated). Transition of the bcc fuel alloy to amorphous or a lower symmetry could induce coalescence of the fission bubbles with consequent fuel swelling, pillowing of the cladding, and disruption of coolant flow.

For the monolithic fuel plate, FCCI is practically non-existent, owing to the zirconium barrier layer between fuel and cladding. This fuel with zirconium barrier layer is being qualified. For U-xMo dispersion fuels, coatings are used to mitigate FCCI; FCCI for dispersion fuel is discussed in a later section. Significant evidence exists that in the absence of these barriers, interaction layers consume large fraction of the fuel and behave poorly with regard to fission gas bubble growth, transitions to amorphous, etc.

The extensive experience with U-xMo alloys, as dispersion and monolithic fuels systems, prompts its continued investigation as a candidate fuel system. In the event U-xMo alloys shows merit upon further reactor analysis, it will be important to develop high temperature irradiation data and to investigate coatings and barrier layers in out-of-pile and in-pile testing.

4.1.2.2 U-10Zr and U-5fissium Alloy Fuels. U-10Zr and U-5 fissium (U-5fs) alloys were developed for use in EBR-II. EBR-II development occurred in part alongside a melt-recycle fuel process. The fissium alloy in fresh fuel simulated the steady-state noble metal fission product concentration in 
melt-recycle fuel from EBR-II. The noble metals in the alloy (in weight percent) are Mo (2.5), Ru (1.5), $\mathrm{Pd}$ (0.5), Rh (0.3), and $\mathrm{Zr}(0.1)$. This alloy performed well with regard to lanthanide fission product migration and FCCI, but the swelling from fission gas-porosity-in the early EBR-II experiments was not accounted for in fuel design. The smear density, i.e., the projected cross-sectional area of fuel on the cladding internal diameter, was high. Consequently, early fuel tests resulted in fuel swelling with excessive deformation of the cladding. Subsequent fuel designs used lower smear densities with U-10Zr alloys with good outcomes. In addition, the recycle program was abandoned while the metal fuels research continued. Consequently, researchers abandoned the U-5fs fuel alloy, despite some promise as a fuel alloy, and this project does not recommend U-5fs for further study in this project in deference to U-10Zr, which was qualified in EBR-II to 10 atom percent burnup.

Researchers conducted extensive investigations on U-10Zr fuel alloy, leading to its qualification up to 10 atom percent burnup (heavy metal). A smear density of approximately $75 \%$ accommodates the fuel swelling and plastic flow. The porosity arising from fission gas and other swelling mechanisms is connected (open) allowing for roughly $75 \%$ of the fission gas to be released to a plenum above the fuel slug. The porosity begins to close, estimated at approximately $30 \%$ burnup. At this high burnup, the fuel would begin to exert pressure on the cladding to cause deformation [Hofman 1994a]. This fuel was not irradiated to such high burnup, but $20 \%$ burnup has been successfully achieved. It may be mentioned that $\mathrm{U}-10 \mathrm{Zr}$ tests were made with rod-type, and not plate-type fuel.

The fuel morphology U-10Zr is more complex than that for U-xMo alloys. Oxygen impurities, present in large part from fabrication methods, stabilize $\alpha-\mathrm{Zr}$ on the fuel rod surface. From low to moderate temperature, alpha uranium (orthorhombic symmetry) alloys with $\mathrm{UZr}_{2}$ throughout the bulk metal. As temperature increases, beta uranium (tetragonal symmetry) appears alloyed with $\mathrm{UZr}_{2}$, and with further temperature increase, finally the bcc phases appear (bcc uranium with dissolve zirconium, bcc zirconium with uranium, and finally completely miscible bcc U-Zr). These phases are found as one moves toward the center of the fuel pin, with increasing proportions of bcc uranium, and with increasing height on the fuel slug (corresponding to increasing axial temperature). At typical operating temperatures, a sizable fraction of the fuel is present as alpha uranium, which corrodes more quickly in water than the cubic (bcc) phase. Consequently, U-10Zr is more suited to liquid metal coolant.

The reference cladding for U-10Zr is HT9 alloy (ferritic-martensitic steel), but it is no longer available commercially. The cladding reacts little with the fuel material. Iron from HT9 cladding ingresses little into the fuel alloy, while the nickel from D9 (austenitic steel) cladding migrates into the fuel alloy substantially. HT9 has very low nickel content. HT9 also outperforms D9 cladding with respect to lanthanide FCCI, likely because of the very low Ce-Ni eutectic (less than 500 C) [Mariani 2011]. For $\mathrm{U}-10 \mathrm{Zr}$, the lanthanide metal fission products migrate to the fuel perimeter en masse, which promotes FCCI. (By contrast, the lanthanide fission products do not exhibit the same extent of migratory behavior in U-5fs as they do in U-10Zr.)

The successful history of U-10Zr irradiations and the continued alloy development under the Advanced Fuels Campaign urge its consideration for the aLEU fuel project. However, its swelling characteristics and limited lifetime (estimated at approximately 30\% burnup because of closed porosity) would require design accommodations that may limit the fuel density. U-10Zr is recommended as at Tier 2 fuel candidate system.

4.1.2.3 U-Nb-Zr Fuels. Researchers worldwide continue to investigate U-Zr alloys for alloy modifications that promote cubic phase retention and mitigate FCCI with both lanthanides and fuels. Very recently research for U-Nb-Zr alloys showed that the cubic phase can be made stable at temperatures below 400 C [Zhou 2019]. This phase behavior indicates that the bcc phase should also be metastable well below $400 \mathrm{C}$, similarly to U-10Mo being metastable as the bcc phase below $250 \mathrm{C}$. The expectation is that corrosion in water would be greatly reduced while fission gas retention in a bubble lattice would be likely. This fuel would then accommodate both water and liquid sodium coolant at high burnup with low 
swelling, an advantage over U-10Zr. This fuel could be used to produce power, because of its similarity to a METMET inert matrix fuel (described in a later section), and because of its definitely stable cubic phase. These fuels offer a significant advantage over the U-xMo alloy fuels with their high-temperature uncertainties for bcc phase retention, fission gas management, and swelling characteristic that need to be assessed for higher temperature, power producing applications.

The alloy composition giving the stable cubic structure at low temperature is approximately $\mathrm{U}_{28} \mathrm{Nb}_{54} \mathrm{Zr}_{18}$ (atomic percent). The calculated uranium density however is very low at $5.6 \mathrm{~g} / \mathrm{cm}^{3}$. If not for the low uranium density, this fuel system is exactly the kind of approach that would allow emergence of an innovative fuel candidate, which could be irradiated in ATR and TREAT should the core size be comparatively small enough. To be clear though, this alloy is not recommended for further study because of its low uranium density. Some novel design reactor feature, such as thermal hydraulics, or some additional alloy development that modeling suggests, are needed to overcome the drawback of the low uranium density before it could be seriously considered. It should however occupy some consideration as the matrix in a dispersion fuel, if it exhibits the desirable high temperature irradiation behaviors that UxMo fuels exhibit at low temperature.

\subsection{Ceramic Fuels}

Metallic fuels captured research fuel interests early on, partly because of their ease of fabrication after the ores are reduced to the metallic state. Issues with onerous, anisotropic swelling soon prompted research into other fuel materials, which burgeoned into a wide range of fuel materials research efforts. $\mathrm{UO}_{2}$ was soon recognized as a viable fuel candidate for its relative ease of preparation and chemical stability toward ambient atmospheric conditions at room and moderate temperatures [Lambert 1994, Belle 1961]. The thermal conductivity of $\mathrm{UO}_{2}$ is remarkably low for oxides, but its irradiation characteristics were found suitable as a fuel. $\mathrm{UO}_{2}$ has a cubic symmetry and the kinetic barriers for returning to cubic symmetry are low enough to resume and retain the cubic structure locally during irradiation. This microstructural feature helps to eliminate the anisotropic and unpredictable swelling observed early for metallic fuels with lower symmetry, and it helps to prohibit transitions to locally amorphous states prone to cavitation swelling. $\mathrm{UO}_{2}$ is also readily adaptable to rod-type and plate-type fuel in monolithic, dispersion and inert matrix forms. Surrounding these successes with a drive toward rapid implementation of nuclear power under government funded support, the $\mathrm{UO}_{2}$ technology infrastructure grew to a very large complex of associated industries.

The design objectives for nuclear fuels driving early nuclear engineers to select, study, and optimize oxides led to development of other high temperature ceramics that would satisfy their criteria. Uranium carbides, generally the monocarbide (UC), were noted as plausible nuclear fuels for many of the same reasons that oxide fuels are successful: high melting point, high actinide density, and reasonable stability under irradiation. Uranium mononitride (UN) caught interest for the same reasons [Blank 1994].

A challenge common to all non-oxide ceramic fuels is susceptibility to oxidation. The stability of the uranium-oxygen bond, and specifically $\mathrm{UO}_{2}$ compared to other uranium compounds, is significant. The practical consequence of this behavior is that most non-oxide compounds of uranium, such as UC and UN among others, will rapidly oxidize and subsequently decrepitate following exposure to an oxidant (e.g., oxygen, water/steam, carbon monoxide). Nevertheless, UC and UN are candidate fuel materials, along with the more stable $\mathrm{UO}_{2}$.

\subsection{1 $\mathrm{UO}_{2}$ Fuel}

$\mathrm{UO}_{2}$ fuels occupy the vast share of nuclear reactor implementations worldwide. $\mathrm{UO}_{2}$ continues to be used in power and research applications. Fuel types employed with $\mathrm{UO}_{2}$ are plate, rod, and particle in all three forms: monolithic, dispersion and inert matrix. A variety of enrichments are used, including natural uranium. Commercial LWRs in the US use enrichments up to approximately 5\% while reactors in Canada 
use natural uranium. Research reactor typically implement HEU (high-enriched uranium) fuels. Many of the research reactors have been converted to LEU, and new reactors are being designed with LEU.

The reactor systems for $\mathrm{UO}_{2}$ are numerous, and $\mathrm{UO}_{2}$ is used in thermal as well as fast reactors. Some versatility of $\mathrm{UO}_{2}$ is demonstrated with applications in gas-cooled, water-cooled, heavy water cooled, and liquid metal cooled reactors. Many LWRs operate according to pressurized water reactor design and boiling water design. In fast reactors, $\mathrm{UO}_{2}-\mathrm{PuO}_{2}$ systems constitute the fuel.

Plate-type fuels present a limitation for $\mathrm{UO}_{2}$ fuels, because it is difficult to fabricate the more dimensionally stable curved plate fuel than flat plate fuel (Figure 3) [Tammaro 1958]. Since $\mathrm{UO}_{2}$ is brittle and does not become ductile until $1100 \mathrm{C}$ or higher, fabrication techniques to produce curve plates could induce modifications to the cladding with adverse consequences on fuel performance (e.g., plate geometry, cladding microstructure, oxidation, etc.). On the other hand, advanced manufacturing may allow for the fabrication of curved $\mathrm{UO}_{2}$ tablets that fit into a curved plate to gain the dimensional stability of plate fuel with coolant flow.

$\mathrm{UO}_{2}$ fuels are considered a candidate fuel system because of the extensive successful experience with it, the huge technology infrastructure that could help implementation, and its low swelling characteristics arising from fission gases. Owing to its prominence in commercial systems, the reactor analyses for $\mathrm{UO}_{2}$ constitute the benchmark for comparing to other candidate fuels systems.

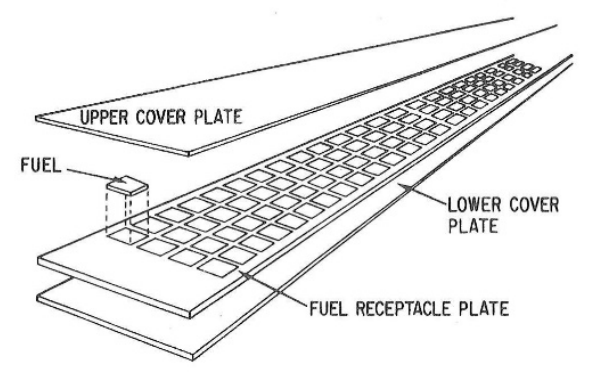

(a)

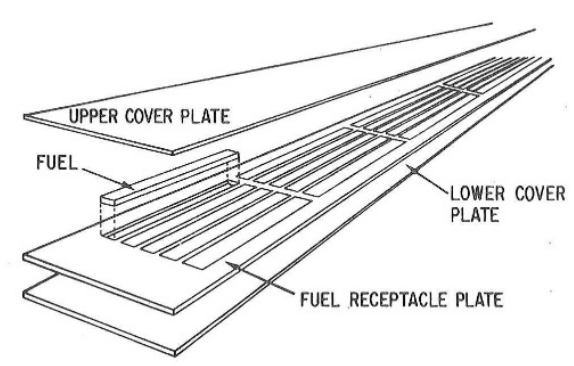

(b)

Figure 3. Schematic representations of cladding and fuel components for compartmented plate-type oxide fuel elements. (a) Caramel fuel for the Osiris reactor; (b) fuel element for the Shippingport reactor [Cherruau 1980]. 


\subsubsection{UC Fuel}

Uranium monocarbide (UC) first rose to initial prominence as nuclear engineers sought fuel concepts that improved upon the breeding characteristics of oxide fuels. Uranium monocarbide possesses a much higher heavy metal density than $\mathrm{UO}_{2}$, a higher thermal conductivity, and only a small reduction in melting point. These factors drove early interest in uranium and plutonium carbides, as well as the potential of carbide fuels present for dispersion in a graphite matrix.

The key operational issues that challenge broader consideration of monolithic UC fuel materials are swelling and carburization of cladding at high burnup. Limited international interest in both breeding and fast reactor technologies has blunted research programs aimed at better understanding and mitigating these challenges. The known material database for UC is reasonably mature and has been summarized [Blank 1994].

Deployment of carbide fuel materials inherently introduces carbon activity that may impact cladding performance. Early in fuel life, the pellet-clad gap will limit the potential for direct interaction, but swelling will rapidly bring the fuel into contact with the cladding. The carbon activity and availability of carbon monoxide will then induce thermodynamic conditions that may favor carburization of stainless steel cladding alloys. Carburization and embrittlement of the cladding would be expected to increase cladding failure rates, and significantly degrade burst strength as relevant to transient performance.

UC has a considerable technology development base, a high thermal conductivity, and a high uranium density, but its technology infrastructure and TRL are not current. UC is recommended as a Tier 2 fuel system candidate.

\subsubsection{UN Fuel}

Uranium mononitride (UN) is often cited as a high-performance nuclear fuel in reactor designs due to its combination of uranium density, melt point, and thermal conductivity. Similar to UC, synthesis and processing of UN powder into dense, single-phase, material holds significant challenges. These challenges have limited the amount of data for UN regarding both its fundamental properties and performance under irradiation.

The uranium-nitrogen binary system contains four reported phases: $U N, \mathrm{UN}_{1.6}, \mathrm{UN}_{1.5}$, and $\mathrm{UN}_{2}$. Of these, UN is the only compound of practical relevance to nuclear fuel applications. The other phases exist only in temperature ranges too limiting for the conditions needed for a nuclear fuel. Unlike most other nuclear materials, UN will dissociate rather than melt.

The role of nitrogen partial pressure on decomposition and melt temperature has been studied given its importance in governing fuel safety. It has been reported that greater than 2.5 atmospheres of $\mathrm{N}_{2}$ are needed to retain congruent melting at the melting point of UN, reported to fall between 3080 and $3120 \mathrm{~K}$ [Okamoto 1997].

In recent decades researchers investigated UN to a limited extent. Property summaries for unirradiated UN were largely compiled in the 1960's, 1970's, and 1980's given the interest in use of UN for a range of reactor applications during that time. Hayes compiled a series of investigations conducted in the 1990's, and these four reports comprise the most common citations. The compilations are divided into physical properties [Hayes 1990a], mechanical properties [Hayes 1990b], transport properties (e.g., electrical and thermal conductivity, diffusivity) [Hayes 1990c], and thermodynamic properties [Hayes 1990d].

In the nearly three decades since the publication of these compilations, the literature for UN grew only occasionally. A recent review provides a more detailed discussion of thermal conductivity, focusing on the effect of porosity and oxygen content [Solntceva 2016]. Study of the unirradiated properties and performance of nitride systems has focused on the effect of plutonium and minor actinides for fast reactor applications, which is limited in its impact. 
The properties of UN during nuclear fuel service also has received limited attention. The majority of data was collected for high temperature test irradiations performed to support lead fast reactor irradiations.

While UN has a high uranium density, high thermal conductivity, and high temperature irradiation history, it is difficult to fabricate and handle, and it has low TRL. For these reasons, UN is considered a Tier 2 candidate.

\subsection{Inert Matrix and Dispersion Fuels}

Inert matrix (IM) fuels consist of isolated regions of fuel material particles (or islands) arranged in a matrix of material that is inert toward the fuel material, cladding, and ideally toward the fission products. Dispersion fuels are similar to IM fuels typically with a randomized arrangement of fuel particles within the matrix; however, for dispersion fuels, the fuel particles and fission products are not inert to the matrix. An example of an IM fuel is $\mathrm{U}_{3} \mathrm{Si}$ in $\mathrm{Zr}$, and an example of dispersion fuel is $\mathrm{U}-9 \mathrm{Mo}$ in a magnesium matrix.

Particle fuels are deployed in both IM and dispersion fuels. They can also be deployed in pebble bed reactors. (Monolithic fuels can also be fabricated using particle fuels, in both conventional and advanced manufacturing processes; therefore, this project has strong interest to develop particle fuel processing equipment as applied to uranium-bearing systems.) Coatings on particle fuels can extend fuel life and improved performance. The U.S. DOE is currently qualifying two particle fuels that employ coatings, TRISO and U-xMo dispersion fuels. As of this writing, the project is not considering pebble bed reactors because of their low TRL. However, these fuel and reactor systems are not altogether excluded, as a pebble bed system may become an emergent, longer-range candidate for an innovative fuel system. For example, fuel materials might be formed into Raschig rings or Raschig saddles and used in a packed bed. This configuration provides a curved plate type fuel with high assurance of turbulent coolant flow.

IM and dispersion fuels provide sustained thermal conductivity over the lifetime of the fuel, and managed swelling and fission gas behavior. These benefits allow for high burnup and extended core life. The limitation of IM and dispersion fuel are a relatively larger core size for power applications. Research reactors, which do not produce power, readily accommodate smaller core size and the use of IM and dispersion fuels.

For LEU fuel materials, the uranium density required indicates high volumetric particle loading, which can be difficult to fabricate and can reduce mechanical integrity. Fuel loadings are typically limited to approximately 60 volume percent, and less in actual practice. Nearest neighbor interactions of fuel particles limit the loading. As the fuel is irradiated, the particles swell, and some fission products are expelled creating a 'halo' effect into the surrounding matrix. As more and more fuel particles and halos interact with each other, the likelihood of adverse interactions with the cladding increases. An optional IM is therefore a regular array of fuel particles within the matrix where the fuel particle sizes and separations are optimized for a core target lifetime and burnup. These analyses have been performed, and they can be augmented in relation to the goals for this project. Based on such an analysis, the project recognizes advanced manufacturing may be well suited to fabricate sample systems that can be irradiated and interrogated with PIE.

IM and dispersion fuels designs vary. IM is categorized as METMET, CERMET, and CERCER, depending on whether the fuel is metallic or ceramic, and whether the matrix is metallic or ceramic. A METMET example is $\mathrm{U}_{3} \mathrm{Si}$ in $\mathrm{Zr}$. A CERMET example is $\mathrm{UO}_{2}$ in $\mathrm{Mg}$. CERCER examples are $\mathrm{UO}_{2}$ in $\mathrm{BeO}$ and $\mathrm{UO}_{2}$ in $\mathrm{MgO}$. A dispersion fuel examples is $\mathrm{U}$-xMo in aluminum alloy (used in Belgian Reactor 2). This survey describes specific systems below, except for CERCERs, as CERCERs have been investigated to lesser extents because of a lower thermal conductivity or a lower uranium density. This project does not recommend CERCER development activities at this time. 


\subsubsection{METMET Fuels}

A METMET fuel comprises metallic fuel particles in a metallic matrix. The behavior of uranium alloys under dispersion condition strongly differs from that of the bulk fuel alloy. Experience gained using these fuels at an industrial scale demonstrated this difference. In the 1950s, a dispersed fuel consisting of a U-9Mo alloy in a Mg matrix began to be used, and this type of fuel has been used for many years in the Bilibinskaya nuclear power plant [IAEA 2003]. Other reactor types have also used such a fuel. In the 1990s, researchers began development programs on METMET fuels with $\mathrm{Al}$ and $\mathrm{Zr}$ as matrix materials.

Dispersion fuels improve the corrosion behavior of the uranium alloys. (See Table 6). The matrix adds protective properties, and it can passivate the fuel material.

Dispersion fuels also positively affect the swelling behavior of the fuel particle, as the solid matrix restrains the fuel particle swelling (Table 7). The mechanical properties of the matrix will play a role, along with the design of the fuel pin and the cladding properties. Experimental data confirms the expected restraining influence of the matrix on the swelling of the uranium alloys.

Table 6. Corrosion rate comparison of uranium alloys in bulk and dispersed forms [IAEA 2003].

\begin{tabular}{|c|c|c|c|}
\hline $\begin{array}{c}\text { Sample } \\
\text { Characteristics }\end{array}$ & Temperature $\left.\mathbf{~}^{\circ} \mathbf{C}\right)$ & Time (h) & $\begin{array}{c}\text { Corrosion Rate } \\
\left(\mathbf{m g} / \mathbf{c m}^{2} \mathbf{h}\right)\end{array}$ \\
\hline U-5Zr-5Nb & 360 & 300 & 0.34 \\
& \multirow{2}{*}{360} & 1000 & 0.58 \\
\hline $\begin{array}{c}62 \text { vol.\% U-5Zr-5Nb } \\
+37 \text { vol.\% Zr }\end{array}$ & \multirow{2}{*}{300} & 1000 & 0.022 \\
\hline $\mathrm{U}_{3} \mathrm{Si}$ & \multirow{2}{*}{300} & 300 & 0.018 \\
\hline 65 vol.\% $\mathrm{U}_{3} \mathrm{Si}$ & 900 & 0.56 \\
+35 vol.\% Zr & & 300 & Destruction \\
\hline
\end{tabular}

As mentioned above, $\mathrm{Mg}$ is an effective inert matrix material. A typical fabrication route involves the filling of cladding with fuel particles followed by the filling the inter-particle voids with molten magnesium. To obtain unusually high particle loading (up to 70 vol\%), vibro-compaction is used to settle and densify the various size fractions. To ensure uranium alloy powders like U-xMo and U-5Zr-5Nb alloys are present as the $\gamma$-phase, the as-fabricated fuels rods are cooled in a controlled fashion.

Table 7. Swelling of uranium alloys in bulk and dispersed forms [IAEA 2003].

\begin{tabular}{|c|c|c|c|c|}
\hline $\begin{array}{l}\text { Fuel Composition } \\
\text { (weight\%) }\end{array}$ & Fuel type & $\begin{array}{c}\text { Average } \\
\text { Irradiation Temp. } \\
\left({ }^{\circ} \mathrm{C}\right) \\
\end{array}$ & $\begin{array}{c}\text { Irradiation Burnup } \\
\left(\mathrm{g} \mathrm{U} / \mathrm{cm}^{3}\right)\end{array}$ & $\begin{array}{c}\text { Swelling Rate (\% } \\
\text { per } 1 \mathrm{~g} \mathrm{U} / \mathrm{cm}^{3} \text { ) }\end{array}$ \\
\hline $\mathrm{U}-5 \mathrm{Zr}-5 \mathrm{Nb}$ & $\begin{array}{c}\text { Bulk rod } \\
\text { Dispersed in } \mathrm{Al}\end{array}$ & $\begin{array}{c}180-220 \\
150 \\
\end{array}$ & $\begin{array}{c}0.28 \\
1.8 \\
\end{array}$ & $\begin{array}{c}63 \\
\sim 30 \\
\end{array}$ \\
\hline U-5Zr-5Nb & $\begin{array}{c}\text { Bulk rod } \\
\text { Dispersed in } \mathrm{Zr}\end{array}$ & $\begin{array}{c}240-280 \\
260 \\
\end{array}$ & $\begin{array}{c}0.26 \\
0.8 \\
\end{array}$ & $\begin{array}{l}150 \\
\leq 15 \\
\end{array}$ \\
\hline $\mathrm{U}_{3} \mathrm{Si}$ & $\begin{array}{c}\text { Bulk rod } \\
\text { Dispersed in } \mathrm{Zr}\end{array}$ & $\begin{array}{c}240-290 \\
250 \\
\end{array}$ & $\begin{array}{l}0.26 \\
0.65 \\
\end{array}$ & $\begin{array}{c}90 \\
\leq 15 \\
\end{array}$ \\
\hline $\mathrm{U}_{3} \mathrm{Si}$ & $\begin{array}{c}\text { Bulk rod } \\
\text { Dispersed in Al } \\
\end{array}$ & $\begin{array}{c}180-220 \\
150 \\
\end{array}$ & $\begin{array}{c}0.26 \\
2.9 \\
\end{array}$ & $\begin{array}{l}20 \\
13 \\
\end{array}$ \\
\hline $\begin{array}{l}\text { U-10Mo } \\
\text { U-9Mo }\end{array}$ & $\begin{array}{c}\text { Bulk rod } \\
\text { Dispersed in Mg }\end{array}$ & $\begin{array}{l}300-400 \\
300-360\end{array}$ & $\begin{array}{c}0.2-0.4 \\
0.3\end{array}$ & $\begin{array}{c}21-43 \\
\leq 20\end{array}$ \\
\hline
\end{tabular}


In an LWR application, the matrix involved a zirconium alloy [IAEA 2003]. Use of this material could maintain the fuel swelling at a minimum level (level of solid swelling which is about 15 vol\% per $g$ $\mathrm{U} / \mathrm{cm}^{3}$ burnup), and it limited the interaction of the fuel with the matrix under irradiation. Table 8 indicates some properties of advanced METMET fuels.

A METMET dispersion matrix can adversely affect the neutronics and consequently economic characteristics of LWR cores because of parasitic capture of neutrons, depending on the cross-section of parasitic isotopes in the matrix elements. If zirconium is used as the matrix, parasitic neutron capture is reduced to approximately 0.5 barn against the data given in Table 8 . As a result, the $U$ content in METMET can be lowered by a factor of 1.3 compared to the values given in Table 8 to the level of commercial $\mathrm{UO}_{2}$ fuel elements. Some extruded METMET fuels yielded particle volume content as high as $50 \%$.

The high reliability of METMET dispersion fuels can compensate for the disadvantages discussed above. When there is mechanical contact between the $\mathrm{Zr}$ cladding and the $\mathrm{Zr}$ matrix one can achieve a radial deformation of the $\mathrm{Zr}$ cladding of about $5 \%$ (instead of $2 \%$ for a free-standing fuel rod with $\mathrm{UO}_{2}$ fuel), and this deformation can accommodate a fuel swelling of $15 \mathrm{vol} \%$. This means that if the fuel particles have a minimum swelling, under restrained conditions, of $\sim 20 \%$ per $\mathrm{g} \mathrm{U} / \mathrm{cm}^{3}$ burnup, there has been an improvement by a factor of two compared to what is typical for a fuel in a commercial LWR.

Table 8. Physical and neutronic characteristics of advanced METMET fuels for LWR (65 vol\% of fuel phase +35 vol. \% of $\mathrm{Zr}$ alloy matrix) [IAEA 2003].

\begin{tabular}{|l|c|c|c|}
\hline \multicolumn{1}{|c|}{ Parameter } & $\mathbf{U}_{3}$ Si & U-5Zr-5Nb & U-9Mo \\
\hline U content in METMET, g/cm ${ }^{3}$ & 9.74 & 9.73 & 10.2 \\
\hline $\begin{array}{l}\text { Thermal conductivity of } \\
\text { METMET, W/(m K) at } 400^{\circ} \mathrm{C}\end{array}$ & $\sim 25$ & $\sim 25$ & $\sim 23$ \\
\hline $\begin{array}{l}\text { Parasitic neutron capture cross } \\
\text { sections, barn per one U atom }\end{array}$ & 0.574 & 0.746 & 1.20 \\
\hline
\end{tabular}

Some performance data for $\mathrm{U}_{3} \mathrm{Si}$ and $\mathrm{U}-9 \mathrm{M}$ o dispersion fuels are listed in Table 9, along with another alloy, U-2Mo-1Si. The U-2Mo-1Si alloy compares very favorably. The U-2Mo-1Si dispersion fuel exhibited a high fission density, good fuel loading, and reasonable porosity.

Table 9. Some design and performance data for advanced fuel rods for small size reactors [IAEA 2003].

\begin{tabular}{|l|c|c|c|}
\hline \multicolumn{1}{|c|}{ Design and Performance Parameters } & U-2Mo-1Si & U-9Mo & $\mathbf{U}_{3}$ Si \\
\hline Volumetric content of fuel alloy, \%/100 & 0.6 & 0.65 & 0.6 \\
\hline Volumetric content of porosity, \%/100 & 0.18 & 0.15 & 0.18 \\
\hline $\begin{array}{l}\text { Uranium content in } \\
\text { composition, g U/cm }\end{array}$ & 11.1 & 10.2 & 9 \\
\hline $\begin{array}{l}\text { Achievable burnup, g U/cm }{ }^{3} \text { for } \\
\text { LEU }\left(20 \%{ }^{235} \mathrm{U}\right)\end{array}$ & 1.55 & 1.43 & 1.26 \\
\hline $\begin{array}{l}\text { Parasitic capture cross section by alloying elements, } \\
\text { barn per U atom }\end{array}$ & 0.45 & 0.98 & 0.34 \\
\hline Thermal conductivity at $400 \mathrm{C}, \mathrm{W} /(\mathrm{m} \cdot \mathrm{K})$ & 18 & 19 & 18 \\
\hline
\end{tabular}


Both $\mathrm{U}_{3} \mathrm{Si}$ and $\mathrm{U}$-xMo are recommended as Tier 1 fuel system candidates. These fuel materials have been extensively investigated. $\mathrm{U}_{3} \mathrm{Si}$ would need to include small alloy additions. Use of $\mathrm{U}_{3} \mathrm{Si}$ relies on a dispersion fuel form, because $\mathrm{U}_{3} \mathrm{Si}$ disproportionates to uranium metal and $\mathrm{U}_{3} \mathrm{Si}_{2}$ at $930 \mathrm{C}$ (Okamoto 1990). This transition temperature reduces the fuel safety margin in a power reactor (as compared to a research reactor), particularly when the dispersion matrix is not an excellent thermal conductor. Both $\mathrm{U}_{3} \mathrm{Si}$ and U-xMo would require more experimental work following their assessment against the benchmark $\mathrm{UO}_{2}$, if the size of reactors they would constitute is favorable.

\subsubsection{CERMET Fuels}

Compared to a standard oxide fuel rod, a cermet fuel has a higher thermal conductivity, which allows for a reduction by a factor of two of the maximum temperature of the fuel [IAEA 2003]. The use of CERMET fuels reduces the energy stored in the reactor core. It is noteworthy that fuel rods with dispersed fuels also have a relatively high operational reliability at variable power regimes. This kind of fuel allows a large accumulation of fission products per fuel volume unit without prohibitive swelling. Dispersion fuels therefore provide for increasing burnup and operational safety in a reactor, and these characteristics allow for a load-following operation.

Research reactors were fueled with CERMETs [IAEA 2003]. For a UN fuel plate, a high uranium density of $7 \mathrm{~g} \mathrm{U} / \mathrm{cm}^{3}$ is typical, and researchers studied fuels with a uranium density as high as $14 \mathrm{~g}$ $\mathrm{U} / \mathrm{cm}^{3}$. Thermodynamic calculations and experiments (separate effects, heat treatment studies) have confirmed the high stability of UN-Al and UN-Zr compounds. UN-Al demonstrated thermodynamic stability at temperatures up to $500 \mathrm{C}$, and $\mathrm{UN}-\mathrm{Zr}$ showed stability at temperatures up to $800 \mathrm{C}$. At higher temperatures, fuel-matrix interactions occur. $\mathrm{UAl}_{3}$ and $\mathrm{UAl}_{4}$ forms at elevated temperatures in fuels with an $\mathrm{Al}$ matrix. Similarly, $\mathrm{UZr}_{2}$ and $\mathrm{ZrN}$ forms at elevated temperatures in fuels with $\mathrm{Zr}$ matrix. Swelling accompanies the reactions. The out-of-pile investigations demonstrated that the UN-Al and UN-Zr dispersions can be considered as candidates for CERMET fuels for the use in research reactors. In the context of CERMETs, UN possesses such a high uranium density that it becomes attractive as a dispersion fuel, which reduces the impact of the fission process and fission product evolution.

Use of high-density ceramic fuels has been historically challenged by two primary factors. First, both UN and UC are vulnerable to degradation and pulverization when subjected to oxidizing environments. This complicates fabrication — as processing and storage of fine powders in air is not possible-and service in reactors that use water coolant; exposure of the fuel to coolant in the event of a cladding breach must be considered. Secondly, fabrication of UN or UC into monolithic forms is more challenging than for oxide fuels. The sensitivity to oxidation requires inert glovebox handling, and fabrication requires higher sintering temperatures. These factors have historically challenged both fundamental research efforts on these fuels and the economics of deployment scenarios.

Deployment of CERMET fuels based on UN or UC is conceivably capable of overcoming the above challenges. Use of a robust metallic matrix alloy could mitigate the challenge presented by coolant interaction, and McMurray demonstrated preparation of stable, high density UN fuel kernels of various sizes [McMurray 2018]. Research efforts will first address fabrication of these CERMET forms based on high density UN or UC particles. Additional coatings research can provide a barrier to mitigate oxidation, fuel-matrix interactions, and possible fission product mobility at high burnup.

\subsubsection{Metal Dispersion Fuels for Small Size Reactors}

Most of the research and test reactors that are designed with plate-type fuel elements employ dispersion fuel. A practical fabrication limit on the dispersed fuel fraction in the core of these elements typically is $~ 50$ vol\% [IAEA 2003]. Calculation shows that a 50\% LEU U-7Mo dispersion can replace an 18\% HEU dispersion. For higher loading replacement, monolithic fuel plates are needed.

Most of the recent development of dispersion fuel involved the conversion of HEU to LEU of Research and Test Reactor fuel (RERTR). A successful phase in this effort was the qualification of LEU 
$\mathrm{U}_{3} \mathrm{Si}_{2}$ dispersed and clad in Al. However, this qualification was done at fairly low power and is not directly applicable to this project. The latest development phase is with U-7Mo alloy spherical particles also in $\mathrm{Al}$ and clad in $\mathrm{Al}$. In the course of irradiation testing it was found necessary to coat the fuel particles with an inert diffusion barrier to prevent fuel-Al interaction. This may be also required for U-xMo/zircaloy dispersion.

Small size nuclear reactors, with a power less than $100 \mathrm{MW}(\mathrm{t})$, attracted attention at the end of the 1950s with the construction of the first propulsion nuclear reactors for the US cargo ship Savannah and the Russian icebreaker Lenin [IAEA 2003]. Significant development of the small size nuclear reactors took place in the 1980's and 1990's. Workers proposed a "barge-mounted reactor" for commercial application, which is based on a design similar to that of the nuclear icebreaker reactor KLT-40S. Equipped with two KLT-40 reactors, the Akademik Lomonosov, a floating nuclear power station with 70 MWe capacity, reached its destination port in Pevek, Russia on 14 September 2019 [Reuters 2019]. On ships with reactors for propulsion, the reactors meet electricity demand shifting from hotel-load to maneuver-power mode as needed.

A dispersion fuel of the type $\mathrm{UAl}_{\mathrm{x}}$ in an $\mathrm{Al}$ matrix (like the fuel for research reactors) fueled the Lenin propulsion reactor. The uranium density was low (about 1 to $1.5 \mathrm{~g} \mathrm{U} / \mathrm{cm}^{3}$ ), and these fuels swelled at a level that was approximately at the level of solid swelling. However, compatibility problems arose due to fuel corrosion in the water coolant in cases where the fuel rods had leaked. This challenge led to the development of other types of metallic uranium alloys that had improved water corrosion resistance. Table 10 lists performance data for some alternative fuel designs.

Table 10. Design and performance data for some metal fuels [IAEA 2003].

\begin{tabular}{|c|c|c|c|}
\hline Properties & U-60Al & U-80Zr & U-50Zr-10Nb \\
\hline Density, g/cm ${ }^{3}$ & 3.8 & 7.8 & 9.1 \\
\hline U content, g U/cm ${ }^{3}$ & 1.5 & 1.6 & 3.6 \\
\hline Achievable burnup & & & \\
(0.7 from all U atoms), g U/cm ${ }^{3}$ & & 1.0 & 2.3 \\
HEU (90\% U-235) & 0.9 & 0.22 & 0.50 \\
LEU (20\% U-235) & 0.21 & & \\
\hline Parasitic capture of neutrons by & & 2.1 & 1.4 \\
alloying elements, barn per U atom & 3.1 & & Stable \\
\hline Corrosion rate in water, mg/(cm $\left.{ }^{2} \mathrm{~h}\right)$ at: & & 0.0007 & 0.002 \\
$300^{\circ} \mathrm{C}$ & Destroyed after & 0.008 & 0.005 \\
$350^{\circ} \mathrm{C}$ & $100 \mathrm{~h}$ & 0.01 & \\
\hline
\end{tabular}

For the U-60Al alloy (60 weight percent $\mathrm{Al}$ ), heat treatment provides a microstructure comprised of $\mathrm{UAl}_{3}$ dispersed in an $\mathrm{Al}$ matrix. Heat treatment of a $\mathrm{U}-80 \mathrm{Zr}$ alloy yields a microstructure with $\delta$-phase $\left(\mathrm{UZr}_{2}\right)$ and a $\mathrm{Zr}$ matrix. For the U-80Zr alloy, irradiation produced a gradual transformation to the $\gamma-\mathrm{U}$ phase (bcc) because of irradiation-induced homogenization and fuel alloying with fission products (mainly Mo and noble metals) that stabilize the $\gamma$-phase. For the U-50Zr-10Nb alloy, the equilibrium microstructure should consist of $\alpha-\mathrm{Zr}+\delta-\mathrm{UZr}_{2}+\gamma-\mathrm{U}$ at temperatures below $500 \mathrm{C}$ (Kurata 1998). Yet, long-term annealing (up to $2000 \mathrm{~h}$ at temperatures below $500 \mathrm{C}$ ) has not produced a corresponding microstructure. Corrosion tests on unirradiated U-50Zr-10Nb alloy samples show very good stability in an aqueous environment when it has the $\gamma$-structure, at the same level of stability as that for unalloyed Zr. 
At moderate temperatures ( $400 \mathrm{C}$ ) U-80Zr and U-50Zr-10Nb alloys swell approximately two to three times more than the expected minimum theoretical solid swelling, and bubble formation causes this. The extent of swelling is less than that for previously discussed uranium-rich alloys, but is, nevertheless, still too high. The fuel discharge burnup (about $1 \mathrm{~g} \mathrm{U} / \mathrm{cm}^{3}$ ) is too high for these alloys, which is twice that of a commercial nuclear power plant, and it is typical for small size nuclear reactors. The swelling of metallic fuel at the end of operation is about 40\% [IAEA 2003].

In addition to swelling, the potential hydrogenation of these irradiated fuel alloys presents another challenge in the case of cladding failure. Hydrolysis along with the simultaneous detrimental action of the temperature and stress fields in the irradiated alloys causes the uptake of some hydrogen into the fuel. Radially oriented hydrides precipitate with radial cracks that grant water access to the central, hottest parts of the fuel. Small size reactor fuel research includes high-density uranium alloys as a dispersion, which Table 9 lists, as these hold more promise.

Currently, the project recommends three high-density metallic fuel systems for an advanced LEU fuel reactor: 1) U-xMo alloys; 2) $\mathrm{U}_{3} \mathrm{Si}$ with minor alloying additions; and 3) U-2Mo-1Si alloys. METMET composite fuels have been found to exhibit very favorable characteristics, with the primary focus on the following matrix materials: $\mathrm{Mg}, \mathrm{Al}$, and $\mathrm{Zr}$. Some CERMET fuels with $\mathrm{UO}_{2}$ have successfully been developed in $\mathrm{Al}$ or $\mathrm{Zr}$ matrices, but the project does not recommend their further consideration because the final uranium density is very low. UC and UN cermet fuels continue to hold interest for their high densities prior to incorporation into the cermet system.

\subsection{Ideal Fuel and Recommended Fuel Systems}

Observations made and fuel systems surveyed allow for ideal fuel system properties to be outlined. For one, a sustained high thermal conductivity provides for load following and steeper power output ramps (less thermal lag). Fuel design should provide for swelling to be curbed or managed and for fission gas to be managed. IM and dispersion fuel systems provide these fuel properties, but with fuel loading lower than a monolithic pellet or plate, typically less than 50 volume percent.

Table 11 lists fuel systems that exhibit most of these properties and that are recommended for further analysis. The high TRL and infrastructure for $\mathrm{UO}_{2}$ urges its continued analysis. Analyses with $\mathrm{UO}_{2}$ will provide a benchmark for the evaluation of other systems. As the benchmark, $\mathrm{UO}_{2}$ system core sizes will be assessed for 100 MWe in both rod and plate-types with both water and liquid metal coolants.

Candidate fuel materials for further evaluation include $\mathrm{U}$-xMo alloys, $\mathrm{U}_{3} \mathrm{Si}$ with additions known to suppress fuel swelling, U-2Mo-1Si alloys and $\mathrm{UO}_{2}$. These are Tier 1 candidates, for reasons indicated in the above discussion and briefly summarized in Table 11.

Another $\mathrm{UO}_{2}$-based system is annular $\mathrm{UO}_{2}$ pellets with inserts and discs separating the pellets (Figure 1). This fuel system mimics IM fuels but achieves very high loadings (greater than 90 volume percent), and modeling has already shown that significantly lower peak temperatures with sustained thermal conductivity will result. The design anticipates better load following, better fission gas retention, and less fuel cracking. Parametric modeling and comparative experiments in TREAT can demonstrate further the clear benefits this system offers. The project recommends this fuel system as a Tier 1 candidate because of the significant advantages that analysis has already shown and the superior TRL for $\mathrm{UO}_{2}$.

U-10Zr ranks as an interesting fuel candidate because it is a qualified, power-producing fuel; however, it has many drawbacks. Overcoming these drawbacks requires only modest analysis and possibly a little experimentation. One concern is the porosity. The ultimate burnup for U-10Zr appears to be 30 percent heavy metal when the porosity closes off and swelling begins to exceed the typical 75\% smear density. Analysis would determine the core size needed for a 30-year core life with this burnup at 100 MWe capacity. On the condition the core size compares favorably with the $\mathrm{UO}_{2}$ core sizes assessed for this project, further analysis could answer a few other questions. What is the cladding thickness 
needed to allow for some cladding wastage resulting from lanthanide migration and FCCI? What is the plenum size needed to manage fission gas evolution? What would the average dpa (displacements per atom) for the cladding be and how does that compare with EBR-II experience? These questions are relatively straightforward and important to address before abandoning U-10Zr since it is a qualified, dense, power-producing fuel. The project recommends U-10Zr as a Tier 2 candidate.

Table 11. Recommended fuel systems.

\begin{tabular}{|c|c|c|c|}
\hline Tier & Fuel Type & Fuel Form & Some Strengths / Weaknesses \\
\hline \multicolumn{4}{|l|}{ Tier 1} \\
\hline $\mathrm{UO}_{2}$ & Rod and plate $^{\mathrm{a}}$ & $\begin{array}{l}\text { Monolithic, dispersion } \\
\text { or inert matrix }\end{array}$ & $\begin{array}{l}\text { Infrastructure, low swelling, power producing / } \\
\text { low thermal conductivity, fuel cracking }\end{array}$ \\
\hline $\mathrm{U}-\mathrm{xMo}{ }^{\mathrm{c}}$ & Rod and plate & $\begin{array}{l}\text { Monolithic, dispersion } \\
\text { or inert matrix }\end{array}$ & $\begin{array}{l}\text { Some infrastructure, high TRL, undergoing } \\
\text { qualification / lacks high temperature irradiation } \\
\text { experience }\end{array}$ \\
\hline $\begin{array}{l}\mathrm{U}_{3} \mathrm{Si} \text { with alloy } \\
\text { additions }\end{array}$ & Plate & $\begin{array}{l}\text { Dispersion or inert } \\
\text { matrix }\end{array}$ & $\begin{array}{l}\text { Some infrastructure, reasonable TRL / fuel density } \\
\text { lowered as dispersion }\end{array}$ \\
\hline U-2Mo-1Si & Plate & $\begin{array}{l}\text { Dispersion or inert } \\
\text { matrix }\end{array}$ & $\begin{array}{l}\text { Some infrastructure, thermal conductivity / little } \\
\text { infrastructure }\end{array}$ \\
\hline \multicolumn{4}{|l|}{ Tier 2} \\
\hline $\mathrm{U}-10 \mathrm{Zr}$ & Rod & Monolithic & $\begin{array}{l}\text { High TRL, thermal conductivity / infrastructure } \\
\text { being reconstituted, porosity limits burnup to } \\
\sim 30 \%\end{array}$ \\
\hline UC & Rod and plate & $\begin{array}{l}\text { Monolithic, dispersion } \\
\text { or inert matrix }\end{array}$ & $\begin{array}{l}\text { Reasonable TRL though not current, dense fuel, } \\
\text { thermal conductivity / no infrastructure }\end{array}$ \\
\hline UN & Rod and plate & $\begin{array}{l}\text { Monolithic, dispersion } \\
\text { or inert matrix }\end{array}$ & $\begin{array}{l}\text { U density, thermal conductivity / no infrastructure, } \\
\text { difficult to fabricate }\end{array}$ \\
\hline \multicolumn{4}{|c|}{$\begin{array}{l}\text { a. Benchmark systems are } \mathrm{UO}_{2} \text { as rods and plates with both } \mathrm{H}_{2} \mathrm{O} \text { and } \mathrm{Na} \text { coolants. } \\
\text { b. Composite systems, as depicted in Figure } 1 \text { are considered, inasmuch as the benefits of dispersion fuel properties are conferred } \\
\text { on the } \mathrm{UO}_{2} \text { monolithic portion with minimal reduction of uranium density. } \\
\text { c. } \mathrm{x}=7,9 \text {, or } 10 \text { weight percent. }\end{array}$} \\
\hline
\end{tabular}

Other systems, with fuel phases to be determined, would comprise a geometrically optimized IM fuel array that might be accessible in practice because of advanced manufacturing. For example, a packaged array of IM fuel might include UC or coated UC particles. The project recommends UC fuels as a Tier 2 candidate, with its high thermal conductivity, because of its dated TRL. Fabrication innovations and analysis for IM array systems can help optimize average uranium density and fuel performance and heighten the relevance of UC. Coated $\mathrm{U}_{3} \mathrm{Si}$ and $\mathrm{U}$-xMo particle fuels attract attention for the same reason. $\mathrm{U}_{3} \mathrm{Si}$ however is recommended only as a dispersion or IM fuel, because of the low transition temperature noted above. Rudimentary analysis of the IM array systems, beginning with the densest fuel system, would permit core size assessments in comparison to $\mathrm{UO}_{2}$ cores and their relevance to this project. Array systems offer options to U-xMo dispersion and IM fuels also, because the high temperature performance of monolithic U-xMo alloys (plate or rod) is uncertain. The IM version of U-xMo alloy could also be compared to monolithic U-xMo alloys. The project recommends UN as a lower priority Tier 2 candidate because of the fabrication challenges it presents. While UC has similar fabrication challenges, UN has an even lower TRL compared to UC.

\section{INITIAL SCREENING OF REACTOR CONCEPTS}

The aLEU fuel project is evaluating viable concepts for high-performance fuel systems and reactor concepts and will assess them relative to the criteria discussed in Sections 2 through 4. Over the course of the project, this effort will involve multi-stage analyses of reactor and fuel concepts, trade study 
evaluations of both deployed and conceptual reactors, and assessments of relevant potential operational or deployment-related considerations. This initial screening summarizes the information to support prioritization of research focus and efforts within the project, helping to ensure that sufficient effort is applied to the most promising concepts.

The analysis tasks of the aLEU fuel project are focused on exploration of the design space parameters, rather than development of a specific reactor design. The initial target reactor size for this project is $100 \mathrm{MWe}$ (350 MWt). Having a target power rating enables the more meaningful and direct comparison of one reactor-fuel system to another. The project's near-term analysis objective is to assess whether a proposed advanced fuel concept is feasible from the standpoints of core performance and safety, and to estimate the in-pile conditions required for eventual fuel qualification. The scoping analyses provide preliminary insights into the relevant overall core characteristics of candidate concepts.

Ultimate applications for the reactor may cover power ratings ranging from 300 MWe to 30 MWe (approximately $1000 \mathrm{MWt}$ to $100 \mathrm{MWt}$ ). Results for the comparative feasibility analyses could be altered upon altering the power requirements. Further feasibility analyses may be conducted, depending on project duration, funding, and schedule. Cumulative, systematic results for three different power levels (300, 100, and $30 \mathrm{MWe}$ ) and combinations of reactor-fuel systems would permit interested parties to assess results for specific applications.

The existing PWR infrastructure and operating experience is significant. External factors - including whole-system engineering considerations - may ultimately determine the suitability of a reactor concept need. These factors might include chemical or radiological hazards of materials (e.g., coolant), system robustness in a seismic or mechanical shock environment, etc. Their evaluation is beyond the scope of the present study. Future studies, hinging on the continuing success of this project, can weigh these factors. For completeness, a broad approach is initially taken to examine more generic fuel and reactor issues for all concepts.

\subsection{Reactor Screening Approach}

One factor for consideration is the extent of development required prior to deployment. It is desirable to avoid a lengthy reactor development program with a series of experiments and prototypes. This factor is important from the standpoint of cost and schedule, the latter being concerned with both long irradiations followed by PIE and demonstrating advanced reactor concepts. Since an off-grid reactor failure is not easily remedied, rapid deployment and demonstrated long life are seen to be competing interests. Innovative systems with little to no prior operational histories will nonetheless be considered, especially if the innovation involves features with high TRLs and histories of high burnup, power applications.

The project uses two early-stage down-selection steps to screen reactor concepts: (1) an overall qualitative screening based on a given concept's prospects for meeting mission requirements, considering relevant information such as its history and relative maturity, allowing for innovative designs, and (2) a simple reactor physics and thermal-hydraulics analysis that provides insight into the relevant overall core characteristics. These two key steps are described in more detail below.

(1) Qualitative screening based on prospects for meeting mission requirements:

The evaluation will apply a balance of three main considerations. First, reactor types that have major unresolved technical problems that require a long-term development program or which are unsuitable for load-following or other key identified performance criteria will be given the lowest priority. Second, high TRL reactor systems with operational experience that will require modification of fuel to higher density fuel material are clearly useful options and provide a set of reference concepts against which more recently-developed innovative alternatives can be compared. Third, advanced reactor concepts aimed at off-grid, load-following applications are worth considering if their characteristics are especially useful. 
The variety of prospective operational environments, radiological, occupational, and chemical hazards, complicate this screening at this early process stage. The initial screening therefore focuses on core and power plant size, core life, and operational characteristics. As mentioned, this screening focuses on core power design of $350 \mathrm{MWt}$ (100 MWe).

(2) Simple reactor physics and thermal-hydraulics assessments:

The analyses performed within the initial screening of reactor concepts provide preliminary insights into the relevant overall core characteristics of candidate concepts. The appropriate thermal-hydraulic limits normally required for safe operation of reactors must be met, including fuel temperature limits and boiling/heat flux limits. Reactivity feedbacks must provide most of the reactivity control for both load-following and related passive safety. Decay heat removal during accidents must be effective using simple systems or procedures.

\subsection{Reactor Summaries and Qualitative Assessments}

As mentioned, the first step in the initial reactor concept screening study was to survey reactor technology concepts. The project surveyed widely-deployed reactor types as well as innovative designs which have been proposed and evaluated to varying degrees but have not yet been produced or deployed. The survey included many of the diverse SMR reactor concepts.

A number of combinations of fuel materials, types, forms, clad, fuel geometry, and reactor coolant are available for application in an SMR. Many private companies are actively investigating advanced reactor concepts, mostly for purposes of grid electricity generation. The Third Way NGO, for example, lists about 50 such efforts [ARIS 2016a, Benhamed 2019]. According to the World Nuclear Association [WNA 2019a], there are three non-military SMRs operating, one each in China, India, and Russia, and five more under construction in the same countries (plus Argentina). An additional nine SMRs with advanced development are nearing construction-readiness (USA, Russia, China, South Korea, and Canada). Another twenty-four SMRs are in the earlier stages of development, some of which are no longer being actively pursued.

The information presented here reflects the results of the initial qualitative reactor screening study. Moving forward, the project will assess information on reactor technologies to guide the research focus. Brief summaries of the key reactor concepts assessed in the initial reactor screening study are provided below.

\subsubsection{Pressurized Water Reactors (PWR)}

Design Description. PWRs are high-pressure Rankine steam cycle systems that employ three heat transport circuits in series, including rejection to the heat sink. Only the reactor coolant is activated; the steam cycle is completely non-radioactive. Water, both the coolant and the moderator, is readily available and easy to purify.

Either HEU or LEU can be used in alloy or dispersion fuels, but commercial power plants use $\mathrm{UO}_{2}$ enriched to under $5 \%$. Rod and plate fuel elements are used in power reactors. Higher enrichments have been used to make cores compact.

History and Maturity of the Technology. PWRs have been in very widespread use both on- and off-grid since the 1950s. There is also wide experience with water moderator and coolant in research and test reactors. Water chemistry in both the reactor cooling system and the steam cycle is well-understood and well-controlled. SMR PWRs have long been used in naval fleets of the US, USSR/Russia, France, the UK, China, and India. The first commercial PWR products were, in fact, extrapolations of the US submarine reactor program. The US, Japan, Germany, and Russia have built or operated icebreaker or merchant cargo ship PWRs, and China is currently building one. Overall, eighteen land-based and seven marine-based advanced LWR SMRs are being designed in Russia, the US, China, India, Korea, Japan, and France [ARIS 2016b]. 
Key Observations Relative to the Screening Criteria. The PWR should be one of the reactor concepts used in assessing the feasibility of advanced LEU fuels, because of compact core size and very high TRL. While there is limited experience with high-assay LEU fuels in the US, it offers compact core size, high TRL, a huge technology infrastructure, thorough knowledge of safety basis, and a significant and growing modeling experience. This significantly high TRL qualifies its use as a point of reference to judge other candidate reactor-fuel systems.

\subsubsection{Boiling Water Reactors (BWR)}

Design Description. BWRs are high-pressure Rankine steam cycle systems that employ only two heat transport circuits in series, including rejection to the heat sink. Water in the steam cycle is activated. Reactor vessels must be tall to accommodate moisture separators above the core. LEU rod fuel elements are used in power reactors. Void feedback to power distributions are addressed in core design to prevent regional power oscillations. Control rods are inserted from below the core and are used for power-shaping.

History and Maturity of the Technology. BWRs have been in widespread use since the 1960s. BWR technical maturity is equivalent to PWRs for large reactor applications but are not of much interest to SMR designers [WNA 2019a]. Neutron activation of water might be an important issue in BWR applications.

Key Observations Relevant to Screening Criteria. The need for moisture separators above the core suggests a tall reactor vessel. The activation of the steam cycle fluid in the core complicates operations and maintenance in certain environments. The core physics is somewhat similar to that of PWRs, so the BWR concept is given a low priority for this project.

\subsubsection{Gas-cooled Thermal Reactors (HTGR)}

Design Description. Because high temperatures are achievable, HTGRs can be used either with a Rankine steam cycle or Brayton direct gas turbine power conversion cycle [Tilliette 1991]. Both $\mathrm{CO}_{2}$ and He have been used as coolants. Because coolant densities are low, high pressures are required to achieve adequate heat capacity, and a separate moderator, graphite, is required. Two fuel forms are of current interest: TRISO particles in pebbles and TRISO particles in graphite prismatic blocks with coolant channel holes [IAEA 2010]. Thorium particles have been used for breeding. Some of the designs use uranium enrichment above $10 \%$. The low power density and the large thermal mass of the graphite contribute to reactor safety.

History and Maturity of the Technology. Two early generations of $\mathrm{UK} \mathrm{CO}_{2}$-cooled reactors are being phased out: Magnox and Advanced Gas-Cooled Reactors, both large and with low-power density. Three pebble-bed He-cooled HTGRs have operated in Germany and China; China is building its second one. Three prismatic He-cooled Rankine cycle variants have operated in the UK, the US, and Japan. Nine SMR variants are being designed in China, Japan, Russia, South Africa, and the US [ARIS 2016b]. Small versions of HTGRs do not exist, which is a major drawback.

Key Observations Relevant to Screening Criteria. To date, HTGR concepts (so far) have low core-average uranium densities with correspondingly large core sizes. The modern HTGR fuel material, TRISO, has a high TRL, but low uranium density due to the thick particle shells. A larger core size might be acceptable if a compact advanced power conversion (e.g., Brayton gas turbine direct cycle) can be used. In such cases, the more compact power conversion system could free up volume that would accommodate the larger core. One interesting example is a transportable integral gas turbine system that Holos proposed in which four subcritical modules, when assembled, operate as a critical reactor [Allen 2018]. This concept could presumably be converted to a single critical unit configuration. The challenges that HTGR systems present do, however, tend to rank them low overall. 


\subsubsection{Heavy Water Reactors (PHWR)}

Design Description. Heavy water reactors use low-pressure $\mathrm{D}_{2} \mathrm{O}$ as a moderator, and either high-pressure $\mathrm{D}_{2} \mathrm{O}$ or $\mathrm{H}_{2} \mathrm{O}$ as a reactor coolant in a secondary Rankine steam cycle. They have large cores to accommodate sufficient moderator and correspondingly low overall power densities and use a pressure tube/calandria core arrangement that eliminates very thick steel components in the primary system. Very low-enriched or natural $\mathrm{UO}_{2}$ fuel results in a high Pu conversion ratio and frequent or on-line refueling and large fuel throughput. Control rods are inserted between pressure tubes.

History and Maturity of the Technology. Canada commercialized PHWRs in the 1960s with its CANDU (Canada Deuterium Uranium Reactor) series of reactors, extrapolating from the CP-3 experiment. Pakistan, India, Romania, Argentina, South Korea, China, and Canada operate PHWRs.

Key Observations Relevant to Screening Criteria. The relatively large overall core size without compensating volume reduction from a compact, conversion cycle makes PHWRs less attractive for remote, off-grid installation and operation. It is possible that a $19.75 \%$ enriched fuel would reduce the core size and/or increase the core lifetime. The technological maturity is an attractive characteristic.

\subsubsection{Molten-salt Reactors (MSRs)}

Design Description. Currently, the most common Generation IV molten salt concept is a liquid fuel core in which the fissile material dissolved in the molten fluoride salt coolant is pumped around a primary cooling circuit [Allibert 2016]. The secondary coolant is usually made up of similar salts as the fuel salt without the fuel mixed in. The fuel fluid achieves a critical mass only while inside the reactor vessel. There is a thermal concept with graphite present in the core region, and a fast-spectrum version with no graphite. To manage fuel, a small portion of the circulating fuel/coolant salt is re-directed through an in-line filtration component that would remove some of the fission products that limit cycle length and/or permit injection of more fertile material (e.g., U, Pu or Th depending on the design) or additional fissile material as needed.

History and Maturity of the Technology. The US operated the Molten Salt Reactor Experiment at ORNL (Oak Ridge National Laboratory) with U-235 from 1965 to 1968, and with U-233 from 1968 to 1969 [Haubenreich 2017]. In-loop filtration was not part of the reactor. Some corrosion issues were identified, but there have been no further test reactors in which to demonstrate those issues as solved. The Aircraft Reactor Experiment (ARE), built in 1954 in the US, operated successfully, but the Inconel 600 used in it corroded too rapidly at operating temperature. ORNL developed the Hastelloy N (a nickel-based alloy), which greatly improved corrosion performance, but it was found to suffer metallurgical problems in a neutron flux.

Key Observations Relevant to Screening Criteria. To overcome the salt corrosion problem, some of the advanced SMR designs are proposed to have an 8-year reactor vessel life, with reactor replacement taking the place of core refueling. Any reactor coolant leak from the primary loop would also be a fission product/uranium/transuranic leak. There is also recent interest in reactors with molten-salt cooling of solid fuel, and fast MSRs have been proposed that might obviate the on-line filtration. Molten salt reactors can in principle reach high power densities. However, the absence of enduring developments gives these reactors an overall low TRL. High temperature fluoride systems have not been demonstrated to have significant lifetimes (i.e., greater than ten years) across all technology systems.

\subsubsection{Gas-cooled Fast Reactor (GFR)}

Design Description. The Generation IV GFR concept uses a high-pressure direct Brayton cycle He gas turbine power conversion system with high thermodynamic efficiency because of its very high outlet coolant temperature.

History and Maturity of the Technology. None have been built, and no imminent implementation is planned [Tsvetkov 2016a]. The design has a low TRL. 
Key Observations Relevant to Screening Criteria. The power conversion systems for the direct cycle concept might have a small enough volume to allow transportability.

\subsubsection{Supercritical Water-cooled Reactor (SCWR)}

Design Description. The SCWR is a Generation IV LWR that operates above the thermodynamic critical point of water, at a pressure of about 3200 PSI, using a direct steam turbine cycle with condensation. The reactor system can be either thermal or fast system at 510-550 C. $\mathrm{UO}_{2}$. Canada has proposed a pressure tube SCWR.

History and Maturity of the Technology. Supercritical water power conversion has been tested in fossil fuel plant, but nuclear reactors have not been built, and no imminent implementation is planned [Tsvetkov 2016a]. Non-nuclear pre-qualification tests have been carried out [CORDIS 2017].

Key Observations Relevant to Screening Criteria. The designs of these systems are at the pre-conceptual or conceptual design stage, so they have low TRL. There is a low reactor cooling system inventory, corresponding to low heat capacity. The major advantage to SCW is how the fluid retains the viscosity properties of the steam while exhibiting liquid properties such as higher thermal conductivity of subcritical water (compared to subcritical steam). The high temperature and pressure challenge vessel design, in addition to corrosion problems associated with high temperature steam. The SCWR concept would probably require blanket fuel elements to maintain a negative void coefficient in case of a loss of coolant accident [Liu 2015].

\subsubsection{Sodium-cooled Fast Reactor (SFR)}

Design Description. The Generation IV SFR uses either oxide or metallic (U-Zr alloy) fuel with liquid metal sodium coolant, normally with a Rankine cycle power conversion system [Hofman 1994, Crawford 2007]. At the 550C reactor temperatures, sodium is low pressure, obviating the thick reactor vessel and primary piping. The thermal conductivity of sodium is very high, so a more compact core is feasible. Either pool plants or loop plants can be used. To ensure that water does not contact the sodium in the reactor cooling system, an intermediate cooling loop that convects heat from the reactor cooling system to the steam generator is generally used. Higher reactor cooling system temperatures produce a higher thermodynamic efficiency than LWRs. Electromagnetic reactor pumps can be used in lieu of mechanical ones and were was used for the intermediate loop in EBR-II requiring zero days of remedial maintenance in thirty years.

History and Maturity of the Technology. Dozens of SFRs have operated around the world. There are three $(10,600$, and $864 \mathrm{MWe})$ currently operating in Russia, one 13 MWe reactor operating and a 500 MWe reactor about to start up in India, one 140 MWt reactor operable in Japan, and one 65 MWe reactor operating in China. Over 20 SFRs have operated in nine countries. The US has operated one full-fledged prototype 20 MWe civil power plant (EBR-II, 1964-1994), in which passive safety with no active safety systems was been demonstrated. No sodium-water problems were encountered. The Fast Flux Test Facility (FFTF) was sodium cooled. The US Navy briefly operated a sodium-cooled submarine propulsion reactor, then switched the ship back to a PWR after about two years of operation. Sodium is of general industrial interest as a heat transfer and storage medium, including for concentrated solar power [Oshima 2016].

Japan has operated two sodium-cooled fast reactors since 1977. The first, Joyo, is a $140 \mathrm{MWt}$ experimental reactor that suffered damage to core components, especially the upper core structure. The second is Monju, a 280 MWe loop-type prototype fast breeder reactor that has a poor operational record. It started up in April 1994 but was shut down 205 days later due to a sodium leak through a thermocouple well. During a subsequent, brief, operating period, it suffered from a refueling equipment failure. [WNA 2019b] 
France has operated two sodium-cooled pool fast reactor power plants. The first, Phenix, was a 170 MWe prototype reactor that operated from 1973 to 2009, with a several-year shutdown for refurbishing. The second, Superphénix, was a 1250 MWe commercial prototype that operated from 1986 to 1998. It was a very ambitious scale-up from Phenix, especially of steam generator configuration. It never operated consistently, due mostly to sodium leaks arising from poor weld material.

The U.S. operated EBR-II, 60 MWt, for thirty years. Shortly after startup, the secondary coolant system (also liquid sodium) leaked molten sodium. Afterwards the reactor operated with zero days remedial maintenance to the sodium system. The smaller size of the reactor size and attending cooling system may have impacted their significant maintenance record.

Key Observations Relevant to Screening Criteria. The high technical maturity of SFRs make it an attractive candidate for this study. Many of its safety strengths are due to the pool-plant configuration, which would presumably consume more space than a loop setup. Sodium melts at approximately $100 \mathrm{C}$, requiring a separate heating system for coolant during startup or restart. Alternatively, Na-K can be used to lower the melting point to room temperature, but its contact with water produces a significantly more energetic reaction than just sodium with water. The more compact size of a $\mathrm{CO}_{2}$ power conversion system, rather than a Rankine steam cycle, however, might allow for a larger reactor system. Although SFR cores can be quite compact, the pool SFR is much larger.

\subsubsection{Lead-cooled Fast Reactor}

Design Description. The Generation IV LFR can use either oxide or metallic fuel with liquid lead or lead-bismuth eutectic (LBE) coolant, normally with a Rankine cycle power conversion system. Lead freezes at about $328 \mathrm{C}$, which is a concern for off-grid operation. When alloyed with bismuth to the eutectic point (44.5\% lead, 55.5\% bismuth), the freezing temperature drops to $123.5 \mathrm{C}$, so this would be the preferred concept. At the $550 \mathrm{C}$ reactor temperatures, lead is low pressure, obviating the thick reactor vessel and primary piping. Either pool plants or loop plants can be used. Higher reactor cooling system temperatures produce a higher thermodynamic efficiency than LWRs.

History and Maturity of the Technology. The Soviet navy operated two different lead-bismuth designs at about 155 MWt on seven submarines [Smith 2016], which were lost due to reactor plant related accidents with fatalities, or otherwise decommissioned after relatively short operating lives. None have operated in the US. The difficulties the Soviets experienced with these reactors stemmed largely from steam-side corrosion, including stress corrosion, from the use of oil-sealed pumps that leaked into the reactor cooling system, and the effects of poor oxygen control on LBE coolant [Zrodnikov, 2000]. No LFRs have operated in the US.

Key Observations Relevant to Screening Criteria. Lead or LBE does not react vigorously with water, as sodium does. Po-210, a highly radioactive alpha-emitter (a 137-day half-life), is an activation product of a bismuth neutron capture reaction. Its presence might present problems in a reactor during operations and maintenance. Other possible lead-alloy coolants are lead-mercury and lead-magnesium, but there is little experience with either of them. In particular, lead-magnesium apparently has unresolved corrosion problems [Czerwinski 2014]. Electromagnetic pumps can be used but are very inefficient. Due to the high density of lead and its alloys, the pool vs. loop plant layout tradeoffs need to be carefully weighed. LBE cores cannot be quite as compact as SFR cores.

\subsection{Initial Analysis of Fuel Systems and Reactor Concepts}

Based on the results of the initial qualitative screening, the project has prioritized a focus on PWR, SFR, and LFR reactor concepts for use in the analysis work. The PWR is well-known and serves as both a low-risk development option and as a reference case for comparison with other systems. The SFR and LFR provide a technological advance with a substantial experience base, allow for exploring loop- and pool-plant options, and permit exploitation of advanced power conversion systems. The combined fuel systems and reactor concepts will be analyzed jointly as outlined in Table 12. Primary coolants to be 
considered are $\mathrm{H}_{2} \mathrm{O}$ and liquid sodium. While not excluded, molten salt reactors and lead-cooled reactors are of limited interest.

Table 12. Planned scoping analyses for selected fuel systems.

\begin{tabular}{|c|c|c|c|c|}
\hline Tier & Fuel Type & Monolithic & $\begin{array}{l}\text { Dispersion or } \\
\text { Inert Matrix }\end{array}$ & Coolants \\
\hline \multicolumn{5}{|l|}{ Tier 1} \\
\hline $\mathrm{UO}_{2}$ & Rod and plate ${ }^{\mathrm{a}}$ & Priority & Yes $^{\mathrm{b}}$ & $\mathrm{H}_{2} \mathrm{O}, \mathrm{Na}$ \\
\hline $\mathrm{U}-\mathrm{xMo}{ }^{\mathrm{c}}$ & Rod and plate & Yes & Priority & $\mathrm{H}_{2} \mathrm{O}$ \\
\hline $\begin{array}{l}\mathrm{U}_{3} \mathrm{Si} \text { with alloy } \\
\text { additions }\end{array}$ & Plate & No & Priority & $\mathrm{H}_{2} \mathrm{O}$ \\
\hline U-1Mo-2Si & Plate & & Yes & $\mathrm{H}_{2} \mathrm{O}$ \\
\hline \multicolumn{5}{|l|}{ Tier 2} \\
\hline $\mathrm{U}-10 \mathrm{Zr}$ & Rod & Yes & No & $\mathrm{Na}$ \\
\hline $\mathrm{UC}$ & Rod and plate & Yes & Yes & $\mathrm{H}_{2} \mathrm{O}, \mathrm{Na}$ \\
\hline UN & Rod and plate & Yes & Yes & $\mathrm{H}_{2} \mathrm{O}$ \\
\hline \multicolumn{5}{|c|}{$\begin{array}{l}\text { a. Benchmark systems are } \mathrm{UO}_{2} \text { as rods and plates with both } \mathrm{H}_{2} \mathrm{O} \text { and } \mathrm{Na} \text { coolants. } \\
\text { b. Composite systems, as depicted in Figure } 1 \text { are considered, inasmuch as the benefits of dispersion fuel properties are } \\
\text { conferred on the } \mathrm{UO}_{2} \text { monolithic portion with minimal reduction of uranium density. } \\
\text { c. } \mathrm{x}=7,9 \text {, or } 10 \text { weight percent. }\end{array}$} \\
\hline
\end{tabular}

The direct cycle He-cooled integral gas turbine system should be reviewed further due to its compact power conversion system, high efficiency, and modular implementation; many of its components appear to be at least near-commercial. The project should also consider other "reach" concepts that suggest higher efficiency, smaller space and weight requirements, or other important advances.

Building on the qualitative assessments, the project will utilize initial screening analyses to further down-select and prioritize concepts. Preliminary screening for the gross core size required to achieve sufficient core lifetime and estimates of reactivity will be accomplished using the WIMS-ANL code [Deen 2004] for unit cell (pin, plate, etc.) analysis. This approach has the advantage of very fast turnaround and simple input.

At the time of this report, ANL (Argonne National Laboratory) has performed a sample analysis of the IAEA reactor conversion benchmark [IAEA 1992], a plate-lattice water-cooled reactor, and found that the WIMS-ANL results are adequately consistent with equivalent but higher-fidelity MCNP (Monte Carlo $\mathrm{N}$-particle) calculations. Core size also depends on thermal-hydraulic limits that reflect how much heat can be safely extracted from a fuel plate or pin. Heat flux limits can be applied, along with power peaking factors and a nominal fuel assembly design, to estimate the minimum core size that meets thermal-hydraulic requirements.

\section{CONCLUSION}

This document describes goals for an advanced LEU reactor, nominally 19.75\% enriched uranium, which comprises a load-following, high burn up, long-life core. The project anticipates deploying single core lifetimes of approximately thirty years capable of producing 100 MWe peak power. From a design perspective, the peak electrical power corresponds to $350 \mathrm{MWt}$ with an efficiency of $28.6 \%$. Assuming an average load of $20 \%$, the thirty-year average power is equivalent to $70 \mathrm{MWt}$ or $20 \mathrm{MWe}$. Applications include portable systems that could supply power to hardened portions of a grid during emergency responses (e.g., to hospitals and drinking water supply systems). The project team qualitatively assessed the known literature to rank fuel and reactor systems and recommends certain systems for further 
evaluation. The upcoming further evaluation includes quantitative assessments through modeling and the identification of knowledge gaps for experimental evaluation.

Using fuel and reactor criteria that support these goals, the project recommends a handful of fuel systems for further study. $\mathrm{UO}_{2}$ is one of the fuels, and its analysis will provide the benchmark to assess other fuel systems. In particular, the analysis of $\mathrm{UO}_{2}$, to assess the size of reactor that will meet the above goals, will form the basis to estimate the potential utility of the alternative fuel candidates, such as UxMo, which are listed in Table 12. Of course, reactor size is only one factor, and the team will conduct a tradeoff study as needed. However, in general terms, a reactor three times larger than a reactor with $\mathrm{UO}_{2}$ is not favorable. Likewise, a reactor that is much smaller than a conventional $\mathrm{UO}_{2}$-based reactor is favorable.

The team identified seven fuel materials as candidates meriting further analysis and experimental study. The fuel forms include monolithic (e.g., alloy), dispersion, and inert matrix. Greater fuel density relates to more compact reactors; monolithic fuels such as U-10Mo therefore attract considerable interest. Fuel swelling in monolithic fuels however challenges the need for dimensional stability in long life cores. Secondary interests therefore include dispersion fuels with high density fuel particles embedded in the matrix, because the matrix can accommodate fuel swelling and heat conduction.

While none of the fuel candidates in their historical implementations perfectly satisfies the aLEU fuel project goals, we ranked seven of them as leading candidates based on fuel criteria set forth here, with recommendations for testing to support their inclusion in future studies. Of course, the ideal tests would show promptly whether a fuel system and its form should be eliminated. For example, irradiating monolithic U-10Mo (as rod or plate) at temperatures consistent with power production would promptly show, if the swelling characteristics are not favorable, that monolithic U-10Mo should be eliminated from consideration. On the other hand, such a result would urge continued and expanded study of U-10Mo in dispersion or inert matrix systems. Likewise, sibling irradiations of $U_{28} \mathrm{Nb}_{54} \mathrm{Zr}_{18}$ could show this fuel material withstands high temperatures and high burnup as expected, enhancing its prospects for consideration as a matrix material in a dispersion fuel. Because of its low density, $\mathrm{U}_{28} \mathrm{Nb}_{54} \mathrm{Zr}_{18}$ is an unsatisfactory fuel candidate, but its use as a matrix material would enhance the volumetric efficiency of the fuel system.

Water and liquid sodium are given primary consideration because of their demonstrated implementations and high TRLs. Gas-cooled systems would require high flows and large pressure drops in a compact, power-producing system. Molten salt coolants present challenges with respect to minimal corrosion and to rapid startup. Supercritical water systems also pose challenges with respect to corrosion and possibly to rapid startup. Several attempts to deploy molten lead coolant yielded no notable successes. The characteristics of these alternatives in comparison to water and liquid sodium indicate a breakthrough is needed in reactor design or materials lifetime for the prospects of their use to improve.

This fuel systems survey also provides a bird's eye view for informing reactor analyses. Similarly, future analyses will inform experimental efforts, i.e., they can help design and prioritize experimental efforts. The project has initiated priority experimental efforts that are facility ready, and the Life Cycle Plan for this project outlines all the experiments planned to date. The team will provide an integrated description of both modeling and experimental plans in a separate Project Plan.

\section{CITATIONS}

[Allen 2018] "Feasibility Study of a Micro Modular Reactor for Military Ground Applications," Kenneth S Allen, Samuel K Hartford, Gregory J Merkel, Journal of Defense Management, 8:172 doi:10.4172/2167-0374 1000172, 2018.

[Allibert 2016] Molten Salt Fast Reactors,” M. Allibert et al. in Handbook of Generation IV Nuclear Reactors, ed. I. Piorio, Woodhead Chapter 20 (2016) , 157-188. 
[ARIS 2016a] Advances in Small Modular Reactor Technology Developments, IAEA Advanced Reactors Information System (ARIS), 2016 Ed. See also, https://neutronbytes.com/advanced-reactordevelopment-projects/, Source Listings of Advanced Nuclear Reactor Development Efforts, March 2019.

[ARIS 2016b] “Advances in Small Modular Reactor Technology Developments: A Supplement to: IAEA Advanced Reactors Information System (ARIS) 2016 Edition,” https://aris.iaea.org/publications/smrbook 2016.pdf].

[Aydogan 2016] “Advanced Small Modular Reactors,” F. Aydogan, in Handbook of Generation IV Nuclear Reactors,, ed. I. Piorio, Woodhead Chapter 20 (2016) 661-699.

[Belle 1961] Uranium Dioxide, Properties and Nuclear Applications, ed. J. Belle, U.S. Atomic Energy Commission, 1961.

[Benhamed 2019] “Fueling America’s Nuclear Energy Leadership,” F. Benahmed and M.G. Soo Tho Third Way Memo, April 16, 2019, https://www.thirdway.org/memo/fueling-americas-nuclear-energyleadership.

[Blank 1994] “Nonoxide Ceramic Fuels,” H. Blank, Chapter 4 in Materials Science and Technology, A Comprehensive Treatment, Volume 10A, Nuclear Materials, ed. R.W. Cahn, P. Hassen, E.J. Kramer, ed. Volume 10A, B.R.T. Frost, VCH, New York, 1994.

[Carmack 2017] "Technology Readiness Levels for Advanced Nuclear Fuels and Materials Development,” W.J. Carmack et al., Nuclear Engineering and Design, 313 (2017) 177-184.

[Cherruau, 1980] "The Caramel Fuel in OSIRIS: The Complete Conversion of a High Flux Research to a Low Enriched Fuel,” Proceedings of the International Meeting on Development Fabrication and Application of Reduced Enrichment Fuels for Research and Test Reactors, F. Cherruau, Argonne, IL, November 1980, 310-344.

[CORDIS 2017] Final Report Summary - SCWR-FQT (Supercritical Water Reactor - Fuel Qualification Test), CORDIS EU research results, https://cordis.europa.eu/project/rcn/97437/reporting/en, record number 97437, accessed June 2019.

[Crawford 2007] "Fuels for Sodium-cooled Fast Reactors: US Perspective,” D.C. Crawford et al., Journal of Nuclear Materials, 371 (2007) 202-231.

[Czerwinski 2014] Corrosion of Materials in Liquid Magnesium Alloys and Its Prevention, by Frank Czerwinski, IntechOpen, https://www.intechopen.com/books/magnesium-alloys-properties-insolid-and-liquid-states/corrosion-of-materials-in-liquid-magnesium-alloys-and-its-prevention

[Deen 2004] WIMS-ANL User Manual, Rev. 6, K.R. Deen, W.L. Woodruff, C.I. Costescu, and L.S. Leopando, ANL/TD/TM99-07, February 2004.

[Glasstone 2012] Nuclear Reactor Engineering, S. Glasstone and A. Sesonske, $4^{\text {th }}$ edition, Vol. 2, 2012, Springer, 611.

[Haubenriech 2017] “Experience with the Molten-Salt Reactor Experiment,” P.N. Haubenreich and J.R. Engel, Journal of Nuclear Applications and Technology, 207, 118-136.

[Hayes 1990a] "Material property correlations for uranium mononitride: I. Physical properties,” S. Hayes, J. Thomas, K. Peddicord, Journal of Nuclear Materials, 171 (1990) 262-270.

[Hayes 1990b] "Material property correlations for uranium mononitride: II. Mechanical properties,” S. Hayes, J. Thomas, K. Peddicord, Journal of Nuclear Materials, 171 (1990) 271-287.

[Hayes 1990c] "Material property correlations for uranium mononitride: III. Transport properties," S. Hayes, J. Thomas, K. Peddicord, Journal of Nuclear Materials, 171 (1990) 288-299. 
[Hayes 1990d] "Material property correlations for uranium mononitride: IV. Thermodynamic properties," S. Hayes, J. Thomas, K. Peddicord, Journal of Nuclear Materials, 171 (1990) 300-318.

[Hofman 1994a] "Metallic Fast Reactor Fuels," G.L. Hofman and L.C. Walters, Chapter 1 in Materials Science and Technology, A Comprehensive Treatment, Volume 10A, Nuclear Materials, ed. R.W. Cahn, P. Hassen, E.J. Kramer, ed. Volume 10A, B.R.T. Frost, VCH, New York, 1994.

[Hofman 1994b] "Dispersion Fuels,” G.L. Hofman and J. L. Snelgrove, Chapter 2 in Materials Science and Technology, A Comprehensive Treatment, Volume 10A, Nuclear Materials, ed. R.W. Cahn, P. Hassen, E.J. Kramer, ed. Volume 10A, B.R.T. Frost, VCH, New York, 1994.

[Hofman 2015] “Dispersion Fuels,” G.L. Hofman and Y.S. Kim, Materials Science and Technology, Wiley-VCH, 2015 (https://doi.org/10.1002/9783527603978.mst0106.pub2).

[IAEA 1992] "Research Reactor Core Conversion Guidebook, Volume 2: Analysis (Appendices A-F)", IAEA-TECDOC-643, International Atomic Energy Agency, Vienna Austria.

[IAEA 2002] "Heavy Water Reactors: Status and Projected Development,” Technical reports series \#407, International Atomic Energy Agency, Vienna, Austria, 2002.

[IAEA 2003] "Development status of metallic, dispersion and non-oxide advanced and alternative fuels for power and research reactors,” IAEA-TECDOC-1374, International Atomic Energy Agency, Vienna, Austria, 2003.

[IAEA 2006] “Fast Reactor Database 2006 Update,” IAEA-TECDOC-1531, International Atomic Energy Agency, Vienna, Austria, 2006.

[IAEA 2010] High Temperature Gas Cooled Reactor Fuels and Materials, IAEA-TECDOC-1645, International Atomic Energy Agency, Vienna, Austria 2010.

[IAEA 2018a] “Advanced Reactors Information System (ARIS),” 2018 Edition, International Atomic Energy Agency, Vienna, Austria, 2018.

[IAEA 2018b] “Advances in Small Modular Reactor Technology Developments,” 2018 Edition, International Atomic Energy Agency, Vienna, Austria, 2018.

[Kurata 1998] Kurata M., Ogata T., Nakamura K., and Ogawa T., Thermodynamic assessment of the FeU, U-Zr and Fe-U-Zr systems, J. Alloys Compd., Vol. 271/273, 1998, 636-640.

[Lambert 1994] “Oxide Fuels,” J.D.B. Lambert and R. Strain, Chapter 3 in Materials Science and Technology, A Comprehensive Treatment, Volume 10A, Nuclear Materials, ed. R.W. Cahn, P. Hassen, E.J. Kramer, ed. Volume 10A, B.R.T. Frost, VCH, New York, 1994.

[Liu 215] "Primary Breeding Ratio Analysis of an Improved Supercritical Water Cooled Fast Reactor, Zijing Liu, Jinsen Xie,and Lihua He, World Journal of Nuclear Science and Technology, 2015, 5, 253-264.

[Mariani 2011] "Lanthanides in metallic nuclear fuels: Their behavior and methods for their control,” R. D. Mariani, et al., Journal of Nuclear Materials, 419, 2011, Pages 263-271.

[Mariani 2017] Accident-tolerant Oxide Fuel and Cladding, R. D. Mariani, US Patent 9,666,310, May30, 2017.

[Mariani 2018] “Annular Accident Tolerant Fuel with Discs and Rod Inserts,” R. D. Mariani, P. Medvedev, and D. L. Porter, Advances in Materials Science for Environmental and Energy Technologies VI: Ceramic Transactions, 262, 195-204.

[McMurray 2018] "Production of Near-full Density Uranium Nitride Microspheres with a Hot Isostatic Press,” J. W. McMurray, et al., J. Am. Ceram. Soc., 101, 2018, 4492. 
[Okamoto 1990] Okamoto H., Si-U (Silicon-Uranium), Binary Alloy Phase Diagrams, II Ed., Ed. T.B. Massalski, Vol. 3, 1990, 3374-3375

[Okamoto 1997] “N-U,” H. Okamoto, Journal of Phase Equilibria, 18, 1997107.

[Oshima 2016] "Sodium-cooled Fast Reactor," H. Oshima and S. Kubo, in Handbook of Generation IV Nuclear Reactors, ed. I. Piorio, Woodhead, Chapter 5 (2016) 97-118.

[Prometheus 2006] Prometheus Project Reactor Module Final Report, SPP-67110-0008, Lockheed Martin and Bechtel, April 24, 2006.

[Reuters 2019] [Reuters 2019] https://www.reuters.com/article/us-russia-nuclear-floatingidUSKBN1VZ0CY, "Russia’s first sea-borne nuclear power plant arrives to its base, Reuters, September 14, 2019.

[Saller 1956] “Properties of a Fissium-type Alloy,” H.A. Saller et al., BMI-1123, 1956.

[Simnad 1981] “A Brief History of Power Reactor Fuels,” M.T. Simnad, Journal of Nuclear Materials, 100 (1981) 93-107.

[Solntceva 2016] E. Solntceva, M. Taubin, V. Vybyvanets, I. Galyov, V. Baranov, O. Homyakov, A. Tenishev, Annals of Nuc. Energy 87 (2016) 799.

[Smith 2016] "Lead-cooled Fast Reactor," CF. Smith and L. Cinotti, in Handbook of Generation IV Nuclear Reactors, ed. I. Piorio, Woodhead, Chapter 6 (2016) 121-155.

[Tammaro 1958] https://babel.hathitrust.org/cgi/pt?id=mdp.39015003403642;view=1up;seq=1 , link to The Shippingport Pressurized Water Reactor Book, Addison-Wesley, Reading, MA, 1958. (Multiple contributors listed. No general editor listed. Foreword by A. Tammaro).

[Tilliette 1991] A Contribution to the H.T.G.R. Energy Conversion Issue,” Z.P. Tilliette, Proceedings of $26^{\text {th }}$ Intersociety Energy Conversion Engineering Conference, Boston MA, American Nuclear Society, August 1991, 1-6.

[Tsvetkov 2016a] “Generation IV USA,” P. Tsvetkov, in Handbook of Generation IV Nuclear Reactors, ed. I. Piorio, Woodhead, Chapter 9 (2016) 223-239.

[Tsvetkov 2016b] “Gas-cooled Fast Reactors,” P. Tsvetkov, in Handbook of Generation IV Nuclear Reactors, ed. I. Piorio, Woodhead, Chapter 4 (2016) 91-97.

[WNA 2019a] https://www.world-nuclear.org/information-library/nuclear-fuel-cycle/nuclear-powerreactors/small-nuclear-power-reactors.aspx Updated May 2019, accessed June 2019.

[WNA 2019b] https://www.world-nuclear.org/information-library/country-profiles/countries-g-n/japannuclear-power.aspx Updated August 2019, accessed September 2019.

[Woolstenhulme 2019] "Development of Irradiation Test Devices for Transient Testing," N. Woolstenhulme et al., Nuclear Technology, 2019.

[Zhou 2019] "Thermodynamic Modeling of the U-Nb-Zr Ternary System,” P. Zhou et al. J. Nuclear Materials, 523 (2019) 157-171.

[Zrodnikov 2000] "Use of Russian Technology of Ship Reactors with Lead-Bismuth Coolant in Nuclear Power”, A. V. Zrodnikov, V. I. Chitaykin, B. F. Gomov, O. G. Grigoryv, A. V. Dedoul, G. I. Toshinsky, Yu. G. Dragunov, and V. S. Stepanov, XA0056724, Russian Federation IAEA TECDOC1172 pp 127-155 (2000). 


\section{BIBLIOGRAPHY}

“The Maturing of Nuclear Fuel: Past to Accident Tolerant Fuel, Progress in Nuclear Energy, Z. Karoutas, et al., 202 (2018) 68-78.

“The Status and Development Potential of Plate-Type Fuels for Research and Test Reactors,” D. Stahl, ANL-79-11.

“U.S. Forward Operating Base Applications of Nuclear Power,” G. Griffith, INL/EXT-15-34351, January 2015.

PWR Core 2 Reactor Design Description Report, ed., R. Atherton, E.J. Kikta and J. Sherman, WAPD-296, March 1968.

“OSIRIS, A MTR Adapted and Well Fitted to LEU Utilization Qualification and Development," M. Barnier and J.P. Beylot, JAERI-M 84-073, 256-267.

“Power Reactors in Small Packages,” W.R. Corliss, United States Atomic Energy Commission, 1968.

A Summary Description of the Fast Flux Test Facility, Compiled by C.P. Cabell, HEDL-400 1980.

Science and technology of advanced LMFBR fuels, H. Matzke, 1986, Elsevier Scientific Publishing Company, New York, United States. 